NBER WORKING PAPER SERIES

\author{
CONSUMPTION COMMITMENTS, UNEMPLOYMENT DURATIONS, \\ AND LOCAL RISK AVERSION \\ Raj Chetty \\ Working Paper 10211 \\ http://www.nber.org/papers/w10211
}

\author{
NATIONAL BUREAU OF ECONOMIC RESEARCH \\ 1050 Massachusetts Avenue \\ Cambridge, MA 02138 \\ January 2004
}

I thank Nava Ashraf, Julie Cullen, David Cutler, Amy Finkelstein, Ed Glaeser, Jerry Green, Jon Gruber, Jens Hilscher, Emir Kamenica, David Laibson, Adam Looney, Casey Mulligan, Jonah Rocko., Emmanuel Saez, Jesse Shapiro, Monica Singhal, Jeremy Tobacman, and especially Martin Feldstein, Gary Chamberlain, Larry Katz, and Caroline Hoxby for helpful discussions and comments. I am also indebted to seminar participants at Berkeley, Chicago, Columbia, Harvard, MIT, Princeton, Stanford, UCSD, and Yale. Philippe Bouzaglou and David Lee provided excellent research assistance. Financial support from the National Science Foundation, Harvard University, NBER, and State Farm is gratefully acknowledged. The views expressed herein are those of the authors and not necessarily those of the National Bureau of Economic Research.

(C2003 by Raj Chetty. All rights reserved. Short sections of text, not to exceed two paragraphs, may be quoted without explicit permission provided that full credit, including $\mathbb{C}$ notice, is given to the source. 
Consumption Commitments, Unemployment Durations, and Local Risk Aversion

Raj Chetty

NBER Working Paper No. 10211

January 2004

JEL No. D8, E21, G1, J6, R21

\begin{abstract}
Studies of risk preference have empirically established two regularities that are inconsistent with the canonical expected utility model: (1) risk aversion over small gambles greatly exceeds risk aversion over larger stakes and (2) insurance buyers play the lottery. This paper characterizes risk preferences both theoretically and empirically in a world with two consumption goods, one of which involves a commitment in that an adjustment cost must be paid when the good is sold. In this model, utility over wealth is more curved locally than globally: individuals are more risk averse with respect to moderate-scale income fluctuations than they are to large income fluctuations. Commitments also create a gambling motive. The empirical importance of commitments is tested using the labor-supply method of estimating risk aversion of Chetty (2003a). Global curvature is imputed using existing labor supply elasticities, and variations in unemployment insurance laws are used to estimate local curvature in a dynamic job search model. Commitments significantly change preferences over wealth: The local coefficient of relative risk aversion is an order of magnitude larger than the global one. Implications for a broad set of questions such as optimal social insurance policies and portfolio choice are discussed.
\end{abstract}

Raj Chetty

Department of Economics

UC- Berkeley

521 Evans Hall \#3880

Berkeley, CA 94720

and NBER

chetty@econ.berkeley.edu 
The United States spent approximately $\$ 200$ billion on social insurance in $2000 .{ }^{1}$ The large size and continued growth of social safety nets in the US and other countries pose an interesting puzzle in public finance. Work by Baily (1978) and Gruber (1997) suggests that the optimal benefit level for unemployment insurance is lower than $20 \%$ of an individual's pre-unemployment wage, and perhaps even $0 .^{2}$ The reason is that empirical estimates of the distortionary costs of unemployment insurance tend to outweigh its consumption-smoothing benefits for reasonable levels of risk aversion. The difference between these theoretical predictions and actual benefit levels, which are around $50 \%$ of pre-unemployment wages, is striking.

This "social insurance puzzle" can be viewed as one manifestation of the general problem of explaining moderate-stake risk aversion using canonical expected utility theory. ${ }^{3}$ Rabin (2000) gives a powerful calibration theorem which shows that expected utility with strictly concave utility over wealth cannot explain observed risk preferences over small and large gambles simultaneously. To take one notable example, an expected utility maximizer who rejects a 50-50 bet of losing $\$ 1000$ and winning $\$ 1010$ will reject a 50-50 bet of losing $\$ 100,000$ or winning any amount. ${ }^{4}$ In other words, the level of risk aversion implied by typical preferences over gambles involving moderate stakes - such as the demand for a substantial amount of unemployment, automobile, and non-catastrophic health insurance - translates

\footnotetext{
${ }^{1}$ Here, I define social insurance as programs that insure income fluctuations. Unemployment Insurance costs were $\$ 25$ billion in 2000 (Source: Ways and Means Green Book 2000); Workers Compensation, $\$ 56$ billion (National Academy of Social Insurance); and Survivors Benefits and Disability Insurance, $\$ 113$ billion (Office of Management and Budget).

${ }^{2}$ This is because the consumption-smoothing benefits of UI are outweighed by its distortionary costs. The zero replacement rate result assumes a coefficient of relative risk aversion less than 2, as estimated e.g. in Chetty (2003a). Higher levels of risk aversion obviously increase the optimal replacement rate.

${ }^{3}$ An alternative view is that social insurance reflects government inefficiency. Those who take this view may prefer to resolve this puzzle using a political economy model that shows why extensive social safety nets emerge even when they do not improve social welfare. This approach is not considered here.

${ }^{4}$ This claim requires that agents reject the $\$ 1000 / \$ 1010$ bet at all wealth levels, but similar results are obtained when the range of wealth levels over which risk preferences are observed is restricted.
} 
into unrealistic levels of risk aversion over larger stakes.

An important assumption in Rabin's calibration argument and in most existing models of risk preference is that agents consume one good, i.e., consumption is a composite commodity. This assumption is innocuous if agents can substitute freely among consumption goods at all times. In practice, however, substituting among goods within a period is costly. Many goods, such as housing and vehicles, involve "commitments" - a transaction cost must be paid to change consumption of these goods. Because of these adjustment costs, families tend to retain most of their commitments during small or short-lived income fluctuations. For instance, Gruber (1998) finds that less than $5 \%$ of the unemployed move out of their homes during a spell.

The central hypothesis of this paper is that incorporating consumption commitments into the expected utility framework can explain the moderate-stake insurance puzzle as well as several other phenomena that are inconsistent with a one-good model. While adjustment costs have been studied in various contexts, their effects on preferences over wealth have not been fully explored. I analyze a model in which agents consume two goods, housing and food. An adjustment cost must be paid to sell a house. The key theoretical result is that agents are relatively more risk averse with respect to moderate-scale income fluctuations than they are to large-scale income fluctuations. The intuition is easiest to see in a model with unrestricted borrowing and saving. In this world, agents rationally choose not to move out of their houses while wealth fluctuates within an $(s, S)$ band defined by their previous housing choice. Since the marginal utility of wealth diminishes more quickly over a smaller set of goods, the "local" curvature of utility over wealth within the $(s, S)$ band is greater than the "global" curvature of utility over wealth outside this band (see Figure 1). For example, if a family needs to reduce total expenditure by $10 \%$ and has pre-committed half of 
its income, they have to reduce spending on items such as food and clothing by $20 \%$. The welfare costs of such a concentrated reduction in consumption can be large, driving up the benefits of insurance within the $(s, S)$ band.

Commitments also rationalize gambling, by effectively generating non-concavities in utility over wealth. The motive for gambling arises because the marginal utility of wealth at $S-\varepsilon$ is lower than the marginal utility of wealth at $S+\varepsilon$. This is because the marginal dollar is spent only on food at $S-\varepsilon$, whereas it is allocated efficiently over both goods at $S+\varepsilon$. Committed agents prefer bets that have big payoffs; fair gambles that have payoffs within the $(s, S)$ band are rejected. The model therefore offers a parsimonious explanation for why insurance buyers also play the lottery, a puzzle potentially related to important economic issues such as real wage rigidity. ${ }^{5}$

To evaluate the empirical importance of commitments for risk preferences, I estimate the local and global risk aversion parameters using the methodology of Chetty (2003a), who shows that the curvature of utility can be inferred from data on labor supply choices. ${ }^{6}$ The key idea is that there is a direct connection between the coefficient of relative risk aversion and the ratio of the income elasticity of labor supply to the wage elasticity, conditional on the degree of complementarity between consumption and leisure. Starting with the case of additive utility - where consumption and leisure are not complementary - Chetty shows that estimates of the coefficient of relative risk aversion are not very sensitive to plausible

\footnotetext{
${ }^{5}$ The lottery-insurance puzzle has posed problems for expected utility theory since its advent. Friedman and Savage (1948) propose nonconcave utility as an explanation for this behavior in defense of expected utility theory. The issue has been revisited more recently by Becker, Murphy, and Werning (1997) and Hartley and Farrell (2002).

${ }^{6}$ The main benefit of using this method of estimating risk aversion is that it permits us to distinguish the commitments model from competing theories of moderate-stake risk aversion such as loss aversion. In particular, local curvature is estimated from wealth perturbations that do not always pass through the kink in a loss-averse agent's utility function. It follows that the high estimate of local curvature is evidence for a higher rate of diminishing marginal utility when agents have commitments, and not simply referencedependent behavior.
} 
perturbations in the complementarity parameter. It follows that data on labor supply choices are sufficient to make inferences about risk aversion at specific wealth levels: in particular, large income effects imply a high degree of curvature. ${ }^{7}$

In the present paper, I first show that existing estimates of labor supply responses to permanent income and wage changes place an upper bound on the global curvature of utility over wealth of 1.25. I then turn to estimating the local curvature parameter. Local curvature can be estimated by observing the labor supply of agents who experience small wage and unearned income fluctuations, during which they are unlikely to move out of their houses or sell their cars. One such group is the set of individuals who experience short spells of unemployment. Differences in unemployment insurance laws across states and time create variation in effective wages and unearned income. Observing the relationship between unemployment durations and these variations permits identification of the income and price effects necessary to infer local risk aversion.

To build intuition on the identification strategy, I first summarize the results of Chetty (2003b), who estimates reduced-form semiparametric hazard models for job-finding after unemployment. These estimates strongly suggest that elasticity of unemployment duration with respect to unearned income is large relative to the wage elasticity, consistent with high local curvature. However, there is no analytic means of translating these reduced-form estimates into a number for local curvature. I therefore estimate the structural parameters of a job search model in which unemployed individuals choose consumption and search effort in each week. Numerical dynamic programming methods are used to compute the optimal search effort path given a set of parameters. A likelihood function for the observed unemployment duration data is constructed from the unemployment exit probabilities that

\footnotetext{
${ }^{7}$ See Chetty (2003a) for further details of the connection between risk aversion and labor supply.
} 
come out of this model, and its parameter set, which includes local curvature, is estimated by maximizing likelihood.

The point estimate of the local coefficient of relative risk aversion in the search model is 7.37 , and the null hypothesis that local and global curvature are equal can be rejected with a $\mathrm{p}$ value less than 0.01 . This result is robust to a number of alternative specifications of the model. Importantly, a comparison of the predicted unemployment exit probabilities with the observed probabilities indicates that the local curvature estimate is identified from precisely the variation in UI laws that one would expect based on the reduced-form analysis, suggesting that the parametric assumptions are not driving the results.

The estimate of local curvature is used to construct an empirical utility over wealth with commitments. This utility escapes Rabin's calibration critique while retaining a consequentalist expected utility framework. Since preferences over wealth are a primitive in a wide set of economic problems, commitments can potentially shed light on a wide range of economic questions, including intertemporal substitution, labor supply responses to taxation, equity risk premiums, and optimal social insurance. For instance, in a standard model of unemployment insurance, the estimate of local curvature implies an optimal replacement rate for pre-unemployment wages of $44 \%$, whereas the canonical one-good model predicts 0 .

The remainder of the paper is organized as follows. Section 1 presents the main theoretical implications of the commitments model for preferences over wealth. Section 2 shows how labor supply data can be used to test this model and derives an upper bound for the global curvature parameter. It also outlines the unemployment insurance law variation used to identify local curvature and reviews the reduced-form results of Chetty (2003b). Section 3 specifies and presents estimates of the dynamic search model. The paper concludes by discussing implications of the commitments model for a set of economic puzzles. 


\section{Commitments and Risk Preferences}

The leading example of a good involving a commitment is housing. Changing consumption of housing typically entails moving expenses and large transaction costs. Broker fees are around $5 \%$ of a home's listing price, and early termination of a lease often entails at least a one month penalty in rent. In addition, leaving a neighborhood and changing children's schools could have direct welfare costs. More generally, any durable good involves some commitment, as market resale values are significantly lower than actual values. The difference between the price of a new car and a one year old car suggests that the loss from reselling a durable is at least $10 \%$ of its value, perhaps due to a lemons problem. ${ }^{8}$ Finally, a number of services require explicit contracts and penalties for early termination - examples include personal health insurance, health clubs, cellular phones, and cable television. ${ }^{9} \quad$ Goods involving commitments comprise a significant portion of most households' budgets. ${ }^{10}$ Table 1 shows that the typical household in the US allocates approximately half of its net-of-tax income to the costly-to-adjust goods described above. ${ }^{11}$

The effects of such adjustment costs on optimal policies have been modelled formally since Scarf's (1959) pioneering work on inventory decisions. In the consumption literature,

\footnotetext{
${ }^{8}$ This figure is based on author's calculations from a sample of twenty 2001 model vehicles sold in the U.S. On average, a one-year old model with 10,000 miles in excellent condition sells for $23 \%$ less than the original sticker price. Assuming straight-line depreciation over ten years, the implied resale loss is $13 \%$.

${ }^{9}$ Late payments do not eliminate commitments. In the event of an income shock, the individual must still eventually pay the bill. The ability to make late payments is as an additional credit channel: it helps only by offering people longer smoothing horizons to dampen shocks.

${ }^{10}$ One may wonder why households choose to commit so much if the welfare costs of income fluctuations are large. Why not rent instead of purchase, in an effort to reduce commitments? This argument ignores market imperfections such as incomplete information, which make ownership advantageous. Glaeser and Shapiro (2002) argue that the agency problems associated with renting create strong incentives for homeownership. Agency costs also explain why it is often rational to purchase rather than rent cars, appliances, and furniture.

${ }^{11}$ At least the first five categories in Table 1 could involve commitments. Certain expenditures, such as health care and education, may be committed or discretionary. As the exact fraction of committed expenditures is not crucial to the analysis that follows, this definition is left open to interpretation.
} 
Grossman and Laroque (1990) show that the low level of covariance between consumption and asset prices can be explained by transaction costs for a durable good. The subsequent literature on illiquid durables has tested this model and found that it provides a good description of many types of consumption decisions; individuals appear to change consumption of illiquid durables infrequently and are responsive to the magnitude of transaction costs. ${ }^{12}$ More recently, Martin (2003) and Flavin and Nakagawa (2003) calibrate a model that has adjustment costs for housing and costless adjustment over food, and find that it fits consumption data better than neoclassical and habit-formation models. However, existing work has not fully explored the effects of commitments on preferences over wealth, in particular the difference between moderate-stake and large-stake risk aversion. ${ }^{13}$

To do so, this section first develops a two-good model of commitments and shows that under certain conditions the agent will follow an $(s, S)$ policy for commitment consumption. I then show that commitments affect risk preferences in two basic ways: they augment risk aversion and create a gambling motive.

\subsection{Model and Consumption Dynamics}

Consider a $T$ period economy with two consumption goods, housing $(h)$ and food $(f)$. Selling a house that provides $h$ units of housing services per period entails a transaction cost $k h{ }^{14}$

\footnotetext{
${ }^{12}$ For instance, Attanasio (2000) estimates an $(s, S)$ model using data from the Consumer Expenditure Survey to show that car stocks are adjusted when non-durable consumption falls to $1 / 3$ of its original level or doubles relative to the current value of the car (e.g. due to depreciation of the capital good). More recently, Ferreira (2003) shows that small variations in property taxes cause significant lock-in effects, reducing homeowner mobility.

${ }^{13}$ Much of the existing work on adjustment costs uses a continuous-time framework with smooth diffusion processes for wealth. Since these studies do not explore the effects of small vs. large gambles, they do not discuss the distinction between local and global risk aversion emphasized here.

${ }^{14}$ It does not matter whether $k$ is a real monetary cost or a psychological cost incurred due to moving. Results also remain identical if the transaction cost is incurred when a good is purchased rather than sold (e.g., an initiation fee).
} 
Choose units so that the price of both $f$ and $h$ is fixed at 1 . Let $u(f, h)$ denote the per-period utility over food and housing, and assume that it satisfies the usual neoclassical regularity conditions: $u$ twice differentiable, $u_{f}>0, u_{h}>0, u_{f f}<0, u_{h h}<0$. Let $W_{t}$ denote wealth at time $t$ and $V_{t+1}\left(W_{t+1}, h_{t}\right)$ the expected continuation payoff from entering period $t+1$ with wealth $W_{t+1}$ and a house $h_{t}$. The agent earns stochastic income $y_{t}$ in period $t$, which may reflect job-related or asset market risk.

The optimal consumption path $\left\{f_{t}, h_{t}\right\}$ can be found using backward induction. In any period $t$ the agent's chooses consumption by solving

$$
\max _{f_{t}, h_{t}} u\left(f_{t}, h_{t}\right)+V_{t+1}\left(W_{t+1}, h_{t}\right)
$$

subject to the intertemporal budget constraint

$$
W_{t+1}=W_{t}+y_{t}-f_{t}-h_{t}
$$

I make two assumptions to simplify the exposition and highlight the key intuitions that arise from the commitments model. First, all uncertainty is resolved in period 1: the agent earns a known income of $y_{t}\left(y_{1}\right)$ that may depend on the realization of $y_{1}$ in all subsequent periods. Second, I abstract from capital market imperfections that prevent the agent from borrowing against future income, and assume that the discount and interest rates are 0 . The effects of these assumptions on the key results are discussed at the end of this section.

To characterize the optimal path of $\{f, h\}$, first observe that the agent's consumption from period 1 onward will be smooth: $f_{t}=f_{1}, h_{t}=h_{1} \forall t>1$. Therefore, the optimal $f_{1}^{*}$ and $h_{1}^{*}$ are functions of the present value of wealth in period 1 , which I denote by $W$, and the previously purchased home, $h_{0}$. 
Solving for the optimal policy for a general specification of the utility function is infeasible. The following assumptions lead to a simple analytical characterization of the agent's consumption decision in period 1.

A1 Inada conditions: $\lim _{f \rightarrow 0} u_{f}=\infty, \lim _{f \rightarrow \infty} u_{f}=0$

A2 Utility $u(f, h)$ has an additively separable representation:

$$
\exists u_{1}, u_{2} \text { s.t. } u(f, h)>u\left(f^{\prime}, h^{\prime}\right) \Leftrightarrow u_{1}(f)+u_{2}(h)>u_{1}\left(f^{\prime}\right)+u_{2}\left(h^{\prime}\right)
$$

The following lemma shows that it is optimal to follow an $(s, S)$ rule for housing choice in period 1 under these assumptions - the agent only sells the house purchased in the previous period if wealth rises or falls above some threshold values.

Lemma 1 A1-A2 $\Longrightarrow \exists s<S$ s.t.

$$
h_{1}^{*}\left(W, h_{0}\right)= \begin{cases}h_{0} & W \in(s, S) \\ \arg \max u\left(f_{1}, h_{1}\right) \text { s.t. } f_{1}+h_{1}=\frac{W-k h_{0}}{T-1} & W \notin(s, S)\end{cases}
$$

Proof. Let $v_{m}(W)$ denote the indirect utility from wealth $W$ when moving and $v_{0}(W)$ denote indirect utility of wealth $W$ if one retains $h_{1}=h_{0}$. Observe that $v_{0}\left(W_{0}\right)>v_{m}\left(W_{0}\right)$ at some wealth level $W_{0}$ where $h_{0}=\arg \max u\left(f_{1}, h_{1}\right)$ s.t. $f_{1}+h_{1}=\frac{W_{0}}{T-1}$. Moving is suboptimal at $W_{0}$ because it results in both lower $f$ and $h$. In addition, using A1, it is easy to show that as $W$ tends to 0 or $\infty, v_{m}(W)-v_{0}(W)$ can be made arbitrarily large, so moving is optimal for sufficiently small or large values of $W$.

An $(s, S)$ policy requires that there are exactly two values of $W$ at which $v_{0}(W)=v_{m}(W)$. The fact that moving is optimal for some small or large wealth levels but not for $W_{0}$ implies via continuity and the Intermediate Value Theorem that there are at least two such values. 
Given differentiability, a sufficient condition for there to be at most two such intersections is that there is at most one wealth level $W$ such that $v_{0}^{\prime}(W)=v_{m}^{\prime}(W)$. The Envelope Theorem implies that $v_{0}^{\prime}(W)=(T-1) u_{f}\left(f_{0}\right)$ where $f_{0}(W)=W /(T-1)-h_{0}$ denotes food consumption at wealth $W$ when not moving, while $v_{m}^{\prime}(W)=(T-1) u_{f}\left(f_{m}(W)\right)$ where $f_{m}(W)$ denotes the optimal food choice when reoptimizing over both $f$ and $h$.

The key step of the proof is to observe that when we choose an additively separable representation of $u, u_{f}(f)=u_{f}\left(f^{\prime}\right) \Longrightarrow f=f^{\prime}$. Hence, it suffices to establish that $f_{0}(W)=$ $f_{m}(W)$, which must be the case because $f_{0}^{\prime}(W)=1>f_{m}^{\prime}(W) \forall W$.

The intuition underlying this result is straightforward. Suppose the agent's experiences a large negative wealth shock in period 1 . Then he will be forced to reduce food consumption drastically in order to maintain the housing commitment that he previously made. Since such a sharp reduction in food consumption causes a large reduction in utility, it becomes optimal to pay the adjustment cost and move into a smaller home. Conversely, if wealth rises sharply, rather than allocating all of his extra wealth to food, whose marginal utility eventually diminishes to zero, he decides to pay an adjustment cost and fully reoptimize his consumption bundle, upgrading to a large house.

When utility is additively separable, the agent is always better off avoiding payment of the fixed cost and staying in the same house when he does not experience a large wealth shock. The separability condition rules out the possibility of oscillation between moving and not moving within this intermediate range. For instance, if $u_{f}(f, h)$ falls sharply when $h$ is significantly above $h_{0}$, it can be optimal to move after moderate increases in wealth but then optimal not to move for slightly larger wealth shocks. Separability rules out such pathologies by making the marginal utility of food consumption independent of the house one owns. Importantly, empirical evidence (see e.g., Attanasio (2000)) confirms that agents 
do follow $(s, S)$ policies over the consumption of illiquid goods that involve fixed adjustment costs. Hence, complementarities between non-commitment and commitment goods do not appear to be large enough to cause deviations from this intuitive policy in practice.

In summary, commitment yields an inaction region over which wealth shocks are borne strictly on the non-commitment (food) margin; outside this inaction region, wealth shocks are split between both goods. The next subsection shows that this feature of consumption has important implications for the agent's induced risk preferences in period 1.

\subsection{Preferences over Wealth}

Let $v(W)=\max \left(v_{m}(W), v_{0}(W)\right)$ denote the agent's indirect utility from wealth $W$ in period 1. This indirect utility function determines the agent's risk preferences. I will show that agents are more risk averse within the $(s, S)$ band than outside the $(s, S)$ band by computing the coefficient of relative risk aversion for these two cases.

Let $\gamma_{f}=\frac{-u_{f f} f}{u_{f}}(f, h)$ represent the coefficient of relative risk aversion over food, which reflects the rate at which the marginal utility of food consumption diminishes at a given point $(f, h)$. Let $\varepsilon_{u_{f}, h}=\frac{-u_{f h} h}{u_{f}}$ denote the negative of the elasticity of $u_{f}$ with respect to $h$, which captures the degree of complementarity between housing and food consumption. Finally, let $\varepsilon_{f, W}$ denote the elasticity of food consumption in period 1 with respect to $W$. With this notation, at any wealth level $W$, the agent's coefficient of relative risk aversion over wealth is given by

$$
\begin{aligned}
\gamma_{W} & =\frac{-v_{W W} W}{v_{W}}=-W \frac{u_{f f} \frac{\partial f}{\partial W}+u_{f h} \frac{\partial h}{\partial W}}{u_{f}} \\
& =\gamma_{f} \varepsilon_{f, W}+\varepsilon_{u_{f}, h} \varepsilon_{h, W}
\end{aligned}
$$


The intuition for (3) is as follows. Utility maximization requires that the marginal utility of wealth equals the marginal utility of food at the optimum; that is, $v_{w}=u_{f}$. Hence, the change in $v_{W}$ from a $1 \%$ increase in $W$ is reflected by the change in $u_{f}$. The marginal utility of food itself changes for two reasons: first, because increased food consumption reduces $u_{f}$ and second, because increased housing consumption affects $u_{f}$. The two terms in (3) correspond to these two effects.

Let us now apply (3) to distinguish risk aversion when the agent retains his housing commitment and when the agent adjusts consumption on all margins. Let $\gamma^{g}(W)$ denote the "global" coefficient of relative risk aversion at wealth level $W$ when an agent adjusts consumption of both housing and food in period 1. Similarly, let $\gamma^{l}(W)$ denote the "local" coefficient of relative risk aversion at wealth level $W$ when the agent chooses to adjust consumption only on the food margin, leaving $h$ fixed at $h_{0}$. It is helpful to distinguish the elasticity of food consumption in the two cases by the same superscripts: $\varepsilon_{f, W}^{l}$ when $h$ is fixed and $\varepsilon_{f, W}^{g}$ when unconstrained. The reason for the local/global terminology will become clear shortly. I make two additional assumptions to characterize preferences over wealth:

A3 Curvature of utility over food is constant: $\gamma_{f}(f)=\frac{-u_{f f} f}{u_{f}}(f)=\gamma_{f} \forall f$

A4 Elasticity of $u_{f}$ w.r.t. $h$ is lower than w.r.t. $f: \varepsilon_{u_{f}, h}=\frac{-u_{f h} h}{u_{f}}<\frac{-u_{f f} f}{u_{f}}=\gamma_{f}$

Lemma 2 A3-A4 $\Longrightarrow \gamma^{l}(W)>\gamma^{g}\left(W^{\prime}\right) \forall W, W^{\prime}$

\section{Proof.}

$$
\begin{aligned}
\gamma^{l}(W) & =\gamma_{f} \varepsilon_{f, W}^{l}=\gamma_{f} \frac{\partial f}{\partial W} \frac{W}{f}=\gamma_{f} \frac{1}{T-1} \frac{W}{f}=\gamma_{f} \frac{W /(T-1)}{f} \\
\gamma^{g}(W) & =\varepsilon_{f, W}^{g} \gamma_{f}+\varepsilon_{h, W}^{g} \varepsilon_{u_{f}, h}
\end{aligned}
$$


Since $\varepsilon_{f, W}^{g}+\varepsilon_{h, W}^{g}=1<\frac{W /(T-1)}{f}$ and A $4 \Longrightarrow \varepsilon_{u_{f}, h}<\gamma_{f}$, it follows that $\gamma^{l}(W)>\gamma^{g}(W)$.

Lemma 2 shows that local curvature is greater than global curvature. To understand this result, let us first focus on the case in which $\varepsilon_{u_{f}, h}=0$, in which case (3) simplifies to $\gamma_{W}=\gamma_{f} \varepsilon_{f, W}$. The difference between local and global risk aversion arises directly from the difference in the wealth elasticity of food consumption in the two cases. When housing consumption is fixed and all wealth shocks are borne strictly on the food margin, a $1 \%$ increase in wealth translates into an increase of $\frac{W /(T-1)}{f} \%$ in food consumption. When agents have commitments, $h_{0}>0$ and $f<\frac{W}{T-1}$, implying that the curvature of utility over wealth is strictly greater than the curvature of utility over food. This is because a $1 \%$ increase in wealth causes food consumption to rise by more than $1 \%$, amplifying the elasticity of marginal utility with respect to wealth. To see this more concretely, suppose a family needs to reduce total expenditure by $10 \%$ because of an income shock. If half of their income has been pre-committed, they have to reduce spending on adjustable items such as food by $20 \%$, raising the marginal utility of wealth sharply.

When both housing and food consumption are adjustable, a $1 \%$ increase in wealth results in an increase of $\varepsilon_{f, W}<1 \%$ in food consumption. The total change in marginal utility is only $\varepsilon_{f, W} \gamma_{f}$, since food consumption goes up by less than one percent for a one percent increase in wealth. The marginal utility of wealth declines more slowly with wealth when both goods are adjustable because the marginal dollar can be allocated more efficiently across different types of consumption. ${ }^{15}$

In the more general case when housing and food consumption are complementary or substitutable $\left(\varepsilon_{u_{f}, h} \neq 0\right)$, we must also take into account the effect of increased housing

\footnotetext{
${ }^{15}$ These results require constant $\gamma_{f}$ because the agent consumes different amounts of food when committed and not committed to a fixed level of housing. If curvature varies with the level of food consumption, the result can loosely be interpreted as stating that "holding fixed food consumption" local curvature is greater than global curvature.
} 
consumption on the marginal utility of food when computing global curvature. If greater housing consumption raises the marginal utility of food $\left(u_{f h}>0\right)$, this effect further lowers $\gamma^{g}$, increasing the difference between $\gamma^{g}$ and $\gamma^{l}$. If housing and food are substitutes $\left(u_{f h}<0\right)$, as long as the marginal utility of food is less sensitive to changes in $h$ than direct changes in $f$ - an intuitively reasonable condition - global risk aversion remains lower than local risk aversion.

Putting Lemma 2 together with the agent's consumption policy yields the first important feature of preferences over wealth with commitments.

Proposition 1 [Local Risk Aversion] Under A1-A4, committed agents are more risk averse locally than globally:

$$
\gamma(W)>\gamma\left(W^{\prime}\right) \forall W \in(s, S), W^{\prime} \notin(s, S)
$$

Proof. Lemma 1 implies the agent will adjust $h$ iff $W \notin(s, S)$. The proposition then follows immediately from Lemma 2.

This result is a straightforward combination of the two lemmas. Small wealth shocks are rationally accommodated over a small base of expenditure, with rapidly diminishing marginal utility. Larger shocks make it optimal to move out of one's house, reducing the rate at which the marginal utility of money deteriorates. ${ }^{16}$ Consequently, "local" curvaturethat is, curvature with respect to small or moderate wealth shocks - is greater than "global" curvature, which reflects risk preferences with respect to large-scale gambles. This property

\footnotetext{
${ }^{16}$ The same intuition carries over to a model with multiple commitments. However, optimal consumption policies in a model with more than one committed good are not simple; for instance, the initial guess that agent's will have a set of $(s, S)$ bands that are progressively larger for goods with larger adjustment costs is not correct. This is because it can be optimal to abandon one large commitment instead of several smaller commitments. What remains true, however, is that utility will be most concave when the agent retains all his commitments and least concave when he does not retain any.
} 
of indirect utility over wealth is illustrated in Figure 1, which plots indirect utility over wealth for a Cobb-Douglas specification of $u$.

The key implication of this result is that expected utility maximizers with commitments can exhibit high degrees of "moderate stakes" risk aversion, in the terminology of Rabin (2000), while having "non-ridiculous" levels of risk aversion over larger stakes. This is in contrast to the implications of expected utility in the canonical one-good model, where Rabin gives a calibration argument which shows that "anything but virtual risk neutrality over modest stakes implies manifestly unrealistic risk aversion over large stakes." The intuition for Rabin's result is that risk aversion over moderate stakes places a lower bound on the rate at which marginal utility of money deteriorates; under the assumption that utility is everywhere concave, risk preferences in the small therefore place constraints on feasible risk preferences in the large. These constraints turn out to be very strong: To take one striking example, an expected utility maximizer who rejects a 50-50 bet of losing $\$ 1000$ and winning $\$ 1010$ must reject a $50-50$ bet of losing $\$ 100,000$ or winning any amount.

Proposition 1 also sheds light on the "social insurance puzzle" that motivated this paper. The value of partial insurance is greater in situations such as temporary unemployment where commitments are retained and income shocks are concentrated on a small fraction of consumption, augmenting the difference between marginal utility in the good and bad states. Generous insurance programs for such shocks may be welfare-enhancing despite the behavioral distortions that they induce. However, for more catastrophic outcomes, such as permanent disability, an increment in insurance coverage may be less valuable because the difference in marginal utility between the good and bad states is not as high.

The reason that moderate-stake fluctuations are of relatively greater concern to committed agents is because there are non-concavities in utility over wealth at the threshold levels 
$s$ and $S$ where the agent abandons his commitment.

Proposition 2 [Gambling Motive]: Under A1-A2, utility over wealth is locally convex at $y_{1}=s$ and $y_{1}=S$ :

$$
\exists \varepsilon>0 \text { s.t. } v_{W}(s-\varepsilon)<v_{W}(s+\varepsilon) \text { and } v_{W}(S-\varepsilon)<v_{W}(S+\varepsilon)
$$

Proof. Take any $\varepsilon>0$. Since $v(W)=\max \left(v_{m}(W), v_{0}(W)\right), v_{w}(s-\varepsilon)=v_{m}^{\prime}(s-\varepsilon)$ while $v_{w}(s+\varepsilon)=v_{0}^{\prime}(s-\varepsilon)$. Since $v_{0}(s+\varepsilon)>v_{m}(s+\varepsilon)$ and $v_{0}(s-\varepsilon)>v_{m}(s-\varepsilon), v_{0}^{\prime}(s)>v_{m}^{\prime}(s)$. Hence, by continuity, $\exists \varepsilon>0$ s.t. $v_{W}(s-\varepsilon)=v_{m}^{\prime}(s-\varepsilon)<v_{0}^{\prime}(s+\varepsilon)=v_{W}(s+\varepsilon)$. An analogous argument establishes that indirect utility is locally convex at $S$.

To see the intuition for why commitments generate a desire to gamble, consider an individual who is deciding whether to buy a candy bar that costs $\$ 1$ or a fair lottery ticket for $\$ 1$ that will pay $\$ 1$ million if he wins. A one good model assumes that the agent will buy one million candy bars if he wins the lottery (or one million units of the composite commodity). This is not optimal because the marginal utility of candy is diminishing, and the agent would be better off getting one candy bar with certainty. However, in a world with commitments, the agent will buy more than just candy if he wins the lottery. While the $\$ 1$ he has in hand cannot be spent to buy a better house or car, the $\$ 1$ million dollars can. ${ }^{17}$

Committed individuals may buy lottery tickets to have a chance at "a new lifestyle" while buying insurance to reduce other types of wealth fluctuations. ${ }^{18}$ The model predicts

\footnotetext{
${ }^{17}$ The kinks in the utility function are an artefact of the assumption that all uncertainty is resolved in period 1. If uncertainty persists, utility will retain non-concavities, but these will be smooth locally convex regions rather than kinks.

${ }^{18}$ Friedman and Savage (1948) were the first to propose non-concave utility as an explanation of the lottery-insurance puzzle. Given economists' predilection for diminishing marginal utility over goods, several models have been proposed as foundations for the Friedman-Savage utility. Kwang (1965) presents a model in which some goods are indivisible, creating an incentive to gamble. Flemming (1969) considers a model
} 
that agents are more likely to prefer lotteries that yield highly skewed outcomes (big payoffs) rather than those that yield small payoffs and do not give the opportunity to drop many commitments. Interestingly, this prediction fits with Golec and Tamarkin's (1998) finding that racetrack bettors "crave skewness."

How do the two propositions change in a richer model where uncertainty persists after period 1 and agents face credit constraints? To answer this question, let us focus on the case where $u_{f h}=0$ and simply assume that the agent follows an $(s, S)$ rule for housing. When uncertainty is persistent, consumption is no longer smooth after the first period. Risk preferences in period 1 are determined by the value function over wealth $v\left(W_{1}\right)$, which is the present value of expected utility from entering period 1 with wealth $W_{1}$. Utility maximization still yields $v_{W_{1}}=u_{f}$, so (3) still applies for the coefficient of relative risk aversion for the value function. But future uncertainty and credit constraints affect the extent to which $\varepsilon_{f_{1}, W_{1}}^{l}$ differs from $\varepsilon_{f_{1}, W_{1}}^{g}$. When the probability of moving in future periods is high - e.g., because of high anticipated variance in wealth $-\varepsilon_{f_{1}, W_{1}}^{l}$ may not be much higher than $\varepsilon_{f_{1}, W_{1}}^{g}$ because it could be optimal to save a large fraction of the extra wealth and use it when buying a new house instead of spending it on food. In essence, the agent can also change future consumption of state-contingent commodities in future periods when he will be outside the $(s, S)$ band, reducing the sensitivity of $f_{1}$ to $W_{1}$ in the current period and attenuating the difference between $\gamma^{l}$ and $\gamma^{g}$. Credit constraints act in the opposite direction by severing the link between current and future periods, further amplifying the effect of commitments on risk aversion. Strong credit constraints reduce the number

of upgrades in which agents consume an illiquid durable whose quality is continually improving over time; in this model, agents' utilities over wealth have non-concavities at each of the points where it is optimal to upgrade. Both the Kwang and Flemming models do not predict high local curvature of utility specific to an agent's initial wealth level, and can therefore be distinguished from the model of this paper using the empirical methodology discussed below. 
of state-contingent commodities over which consumption can be adjusted, forcing greater concentration of adjustment on $f_{1}$ if $h$ remains unchanged.

The theoretical results suggest that commitments may induce important changes in preferences over wealth, but give little guidance on the magnitude of this effect. In view of (??), one indirect method of testing the model's importance is to compare $\varepsilon_{f, W}$ within and outside the $(s, S)$ band. Flavin and Nakagawa (2003) and Martin (2003) essentially implement such a test by showing that the dynamics of food consumption correspond much more closely to those predicted by the commitments model than to a neoclassical model without adjustment costs.

In the remainder of this paper, I take a more direct approach to analyzing the empirical relationship between commitments and risk preferences by estimating local and global curvature. Since $\gamma^{l}$ and $\gamma^{g}$ are sensitive to the specification the credit constraints and underlying process for wealth, I incorporate these features into the estimation procedure by choosing parameters that, if at all, bias against finding $\gamma^{g}<\gamma^{l}$. Using the resulting estimates, I report numbers for local and global curvature that apply to the benchmark case modelled above, in which there is no uncertainty in future periods and no credit constraints. ${ }^{19}$

\section{Testing the Model}

While the commitments model offers an explanation for the difference between local and global risk aversion, other theories can also explain the same facts. ${ }^{20}$ This section shows how the commitments theory can be distinguished from competing models empirically, and

\footnotetext{
${ }^{19}$ Once $\gamma^{l}$ and $\gamma^{g}$ are known for this benchmark case, it is easy to infer risk preferences for other specifications of the model.

${ }^{20}$ Machina (1987) and Camerer (1992) review other non-expected utility theories that have been proposed as explanations for modest-scale risk aversion.
} 
evaluates the importance of commitments as a determinant of preferences over wealth.

The leading existing explanation of moderate-stake risk aversion is loss-aversion, advocated by Rabin (2000) among others. The utility of loss averse agents is a function of changes in consumption from a reference point rather than levels of consumption. The utility benefit of increases in consumption is smaller than the utility loss of corresponding reductions. This creates a kink in utility at the reference point, making agents locally risk averse. $^{21}$ The commitments model is not inconsistent with loss aversion. In fact, it is quite clear that certain types of behavior are not the result of commitments and must come from reference-dependent behavior. For instance, the "first-order" risk aversion over very small stakes (\$10-\$100) documented by Kahneman and Tversky (1979) cannot arise from commitments because utility remains locally linear in this model. I therefore attempt to show that commitments are an important determinant of preferences over moderate-stake risks, and do not falsify the potential importance of loss aversion in explaining other aspects of preferences.

I test the commitments model by estimating the difference between local and global curvature. The standard loss aversion model does not predict that utility is highly curved away from the individual's reference point, whereas the commitments model (which does not have an explicit notion of reference points) predicts a high degree of curvature throughout the $(s, S)$ band..$^{22}$ I show below that the estimates of $\gamma^{l}$ are at least partially identified from perturbations in wealth that are strictly below the reference point, implying that $\gamma^{l}>\gamma^{g}$

\footnotetext{
${ }^{21}$ More precisely, loss aversion must be coupled with "narrow bracketing" - treating individual decisions as isolated events - to explain local risk aversion. While loss aversion is typically a direct assumption about preferences, Brunnermeier (1997) shows that boundedly rational agents with neoclassical preferences can exhibit loss aversion.

${ }^{22}$ In fact, Brunnermeier's (1997) model of loss aversion as an explanation of local risk aversion predicts that utility is convex below the reference. Other non-expected utility theories that explain local risk aversion (reviewed e.g. in Machina, 1987) also do not predict that utility is highly curved locally.
} 
is evidence for commitments and a high rate of diminishing marginal utility over moderate wealth gains, rather than loss aversion.

Implementing this test requires a method of estimating the curvature of utility at various wealth levels. I apply the methodology of Chetty (2003a), who shows that the curvature of utility can be estimated from data on labor supply choices. The key idea is that there is a direct connection between the coefficient of relative risk aversion and the ratio of the income elasticity of labor supply to the wage elasticity, conditional on the degree of complementarity between consumption and leisure. Starting with the case of additive utility, Chetty shows that estimates of the coefficient of relative risk aversion are not sensitive to plausible perturbations in the complementarity parameter. It follows that data on labor supply choices can be used to make inferences about risk aversion at specific wealth levels, restricting attention to the case in which utility is additively separable in consumption and leisure.

In the present paper, I extend this methodology to estimate local and global curvature when agents have commitments. The basic strategy is to estimate global curvature from large changes in income and wages that induce agents to move out of their $(s, S)$ bands, and estimate local curvature from small variations in income and wages during which agents retain commitments. ${ }^{23}$

\subsection{Estimation of Global Curvature}

To see how global curvature can be estimated from labor supply behavior, let us introduce a binary labor-leisure decision into the $T$ period model of housing and food consumption above. For expositional simplicity, assume that utility is additive in consumption and leisure, i.e.

\footnotetext{
${ }^{23}$ In a model with more than one committed good, utility over wealth will have a spectrum of curvatures, ranging from local to global, as the degree of commitment falls. In this world, $\widehat{\gamma}^{g}$ is an estimate of curvature near the right end of the spectrum, while $\widehat{\gamma}^{l}$ is an estimate nearer to the left end.
} 
the cross-partial between consumption and leisure is $0 .^{24}$ I adopt the following notation: $l=0$ when the agent does not work and $l=1$ when he does; $\psi$ denotes disutility of working; $y$ is unearned income; and $w$ is the net-of-tax wage. I assume that unearned income and wage are constant over time.

Let us focus on labor supply decisions in period 1, which are made after agents have made commitments in period 0. Suppose there is heterogeneity among agents in disutility of labor: $\psi \sim f_{0}(\psi)$. As a result of this heterogeneity, some agents who enter period 1 would have been working in the previous period and some would not. I will be interested in calculating the effects of (1) an increase in the wage $w$ and (2) a reduction in unearned income $y$ on labor supply in period 1. Since both of these changes only increase the incentive to work, agents who were already working prior to this change will not change labor supply. ${ }^{25}$ Hence, it is sufficient to focus on the set of agents who were not working prior to these unanticipated perturbations.

To begin, assume that all individuals would move if they were to start working, i.e. $S<T(y+w) .{ }^{26}$ Under this assumption, an agent will begin working in period 1 iff

$$
\psi<\widehat{\psi}(y, w) \equiv v\left(T(y+w)-k h_{0}\right)-v(T y)
$$

\footnotetext{
${ }^{24}$ Using data on consumption choices when employment is stochastic, Chetty (2003a) shows that relaxing this assumption changes the estimate of $\gamma$ by at most 0.25 for plausible values of the complementarity parameter. In the interest of space, I consider only the $u_{c l}=0$ case in this paper.

${ }^{25} \mathrm{An}$ interesting feature of the commitments model is that wage increases and decreases need not have effects of the same magnitude. The left and right derivatives of the labor supply function need not be equal because the non-convex adjustment cost makes the marginal agent who responds to a wage increase differ from the marginal agent who responds to a wage decrease. To compute curvature, we need to focus on the same set of marginal agents - this is why I consider the effects of an increase in $w$ and a decrease in $y$. However, in the empirical implementation, I do not distinguish between decreases and increases because existing studies of labor supply have not documented systematic asymmetries in labor supply elasticities.

${ }^{26}$ Although individuals may not literally move out of their homes, they may buy a new car or new furniture using their higher incomes. In the two good model, $h$ should be interpreted as an aggregate of all these types of consumption.
} 
where $\widehat{\psi}(y, w)$ is the disutility of labor for the agent who is indifferent between working and not working at wage $w$ and unearned income $y$. The fraction of agents who will begin working in period 1 at a given wage $w$ is

$$
\theta(y, w)=\int_{0}^{\widehat{\psi}(y, w)} f(\psi) d \psi
$$

where $f(\psi)$ denotes the distribution of disutility of labor among agents who were not working in period 0 . Now, consider the effect of a small increase in the wage $w$ on $\theta$ :

$$
\frac{\partial \theta}{\partial w}^{+}=f(\widehat{\psi}) v_{W}\left(T(y+w)-k h_{0}\right)
$$

Similarly, the effect of small reduction in $y$ is:

$$
{\frac{\partial \theta^{-}}{\partial y}}^{-}=f(\widehat{\psi})\left\{v_{W}\left(T(y+w)-k h_{0}\right)-v_{W}\left(h_{0}, y-k h_{0}\right)\right\}
$$

It follows that

$$
\frac{\partial \theta}{\partial y} / \frac{\partial \theta}{\partial w}=\frac{v_{W}\left(T(y+w)-k h_{0}\right)-v_{W}(T y)}{v_{W}\left(T(y+w)-k h_{0}\right)}
$$

This expression captures the connection between labor supply and risk aversion that drives the empirical strategy of this paper. It shows that the percent change in marginal utility of wealth from $T y$ to $T(y+w)-k h_{0}$ is equal to the ratio of the income and wage effects on labor supply. The intuition for this relationship can be seen by considering two extreme cases. If agents are risk neutral, the marginal utility of wealth is constant, and the level of unearned income would not affect labor supply decisions; in this case, we would observe $\frac{\partial \theta}{\partial y}=0 . \quad$ At the other extreme, if agents are very risk averse, utility is very curved, and a small reduction in unearned income creates a strong incentive to start working, resulting in a 
large income effect. More generally, the degree of risk aversion is directly related to the size of the income elasticity. Since the income effect confounds risk aversion with the density of disutility of labor $f(\widehat{\psi})$, we must normalize it by the wage effect to infer the shape of utility over wealth.

Since the marginal utilities being compared in (8) are at points where the agent has fully optimized consumption over food and housing, this experiment informs us about the global curvature of utility over wealth. Translating (8) into a formula for the more familiar coefficient of relative risk aversion $\gamma^{g}=-\frac{v_{W W}}{v_{W}} W$ is a straightforward algebraic exercise. Let $l$ denote the overall fraction of agents working in period 1 (including those who were already working in period 0 ). It follows that

$$
\frac{\partial \theta}{\partial y} / \frac{\partial \theta}{\partial w}=\frac{\partial l}{\partial y} / \frac{\partial l}{\partial w}=\frac{\varepsilon_{l, y}}{\varepsilon_{l, w}} \frac{w}{y}
$$

where $\varepsilon_{l, y}$ denotes the elasticity of labor supply with respect to unearned income and $\varepsilon_{l, w}$ the elasticity of labor supply with respect to the wage. With this notation, assuming that the agent has CRRA utility over wealth when he does not have commitments, it is shown in the appendix that we obtain the following estimator for global risk aversion: ${ }^{27}$

$$
\widehat{\gamma}^{g}=\frac{\log \left[1-\frac{\varepsilon_{\theta, y}}{\varepsilon_{\theta, w}} \frac{w}{y}\right]}{\log \left[1+\frac{w-k h_{0} / T}{y}\right]}
$$

This estimator applies when all of the agents sell their homes after they decide to start

\footnotetext{
${ }^{27}$ The functional form assumption is necessary because we are making an inference about second derivative properties of utility from a discrete change in wealth. CRRA utility over wealth is obtained when $u(h, f)$ is homothetic. If $u$ is not homothetic, $\gamma^{g}$ can be interpreted as the best-arc-fit (CRRA) utility function for the difference in marginal utility of wealth when the agent is working and not working. Loosely speaking, $\gamma^{g}$, is the "average" coefficient of relative risk aversion over this range, and $\widehat{\gamma}^{g}$ gives an upper bound for this average.
} 
working. In the more general case in which there is heterogeneity in the upper wealth cutoff for moving, $S$, the estimator $\widehat{\gamma}^{g}$ is an average of the risk aversions of all the agents who change their labor supply. ${ }^{28}$ Letting $\gamma^{l}(W)$ denote the (local) coefficient of relative risk aversion for the agents who do not move, we know that $\gamma^{l}>\gamma^{g}$ from Proposition 1. Hence, when some agents do not drop their commitments, there is a weight $\pi \in[0,1]$ such that

$$
\widehat{\gamma}^{g}=(1-\pi) \gamma^{l}+\pi \gamma^{g} \geq \gamma^{g}
$$

It follows that when some agents move in response to the perturbations in $y$ and $w$ and others do not, the estimator $\widehat{\gamma}^{g}$ gives an upper bound for true global curvature, $\gamma^{g}$.

Chetty (2003a) implements the estimator in (9) and a similar formula for intensive labor supply responses using a diverse set of wage and income elasticities from the existing literature on labor supply. ${ }^{29}$ The measures of labor supply include hours worked, participation, and earned income. The source of identification for these elasticities includes welfare reforms, tax changes, cross-sectional variation, and large lottery payouts. Importantly, the labor supply changes induced by these variations tend to result in large, long-term changes in income. Agents are likely to move out of their $(s, S)$ bands when their adjustments in labor supply induce significant shifts in lifetime wealth. Consequently, the curvature estimate derived from these "static" labor supply elasticities is likely to tightly bound the true global curvature of utility, $\gamma^{g} \cdot{ }^{30}$

\footnotetext{
${ }^{28}$ See Chetty (2003a) for a proof.

${ }^{29}$ Since he is considering a one-good world, Chetty's estimates effectively assume $k=0$. However, a simple calibration shows that accounting for the effect of the adjustment cost does not affect the estimates of $\gamma^{g}$ much. Recalling that $h$ denotes the flow of services from a house, suppose the adjustment cost is $10 \%$ of the house's value, $T h$. Then $k h=0.1 T h \Rightarrow k / T=0.1$. Suppose the agent has committed $50 \%$ of his income prior to period 1 , so $h=0.5 y$. Then the mean estimate of $\gamma^{g}$ rises from 1 to 1.02 . The insensitivity comes from the fact that the adjustment cost is small relative to the change in lifetime wealth.

${ }^{30}$ One may be concerned that intensive labor supply responses will not create a sufficient change in income
} 
Chetty finds an (unweighted) mean estimate from the static labor supply literature of $\widehat{\gamma}^{g} \approx 1$. In addition, he gives a calibration argument showing that if the uncompensated labor supply curve is upward sloping (as almost all studies of labor supply find), $\widehat{\gamma}^{g}<1.25$. The intuition for this argument is simple: if the uncompensated labor supply is upward sloping, the Slutsky equation bounds the magnitude of the income elasticity relative to the wage elasticity. Since the coefficient of relative risk aversion depends on the ratio of these two elasticities, the fact that the labor supply curve is upward sloping effectively places an upper bound on the curvature of utility.

In summary, permanent, large increases in income do not appear to reduce labor supply much, implying that the taste for consumption deteriorates slowly with wealth when agents are able to change commitments. In other words, utility is not very curved globally.

\subsection{Estimation of Local Curvature}

In analogy with the method used to ascertain $\gamma^{g}$, local risk aversion can be inferred from the labor supply behavior of a group of agents who experience small wage and unearned income fluctuations. One such group is individuals who experience short spells of unemployment. ${ }^{31}$ These agents stochastically choose labor supply by deciding how intensely to search for a job.

to cause agents to drop their commitments. In this case, using intensive labor supply responses could reduce $\pi$ and bias the curvature estimate upward, toward $\gamma^{l}$. In practice, this problem is mitigated by the fact that most labor supply changes, even on the intensive margin, tend to be lumpy - individuals work an extra day of the week when their wage rises, not an extra hour. Interestingly, Chetty (2003a) estimates $\gamma=1$ when labor supply is measured by hours worked versus $\gamma=0.3$ when using participation elasticities. This is consistent with the commitments model.

${ }^{31}$ This group may not be representative of the general population. However, if anything, agents who experience unemployment should be less risk averse than the typical person, insofar as they selected into an occupation with greater risk of unemployment. This effect would only bias the estimate of local curvature downward from the population mean. Moreover, the calibration argument used to bound $\gamma^{g}$ applies equally well to agents who experience unemployment as it does to the general population; consequently, selection bias into the sample of UI recipients cannot be driving the results. 
The effects of unearned income and changes in wage rates on search behavior allow us to infer the curvature of their underlying indirect utility function. Since evidence from Gruber (1998) indicates that most individuals retain commitments during short unemployment spells, the curvature estimate from these elasticties will approximate $\gamma^{l} .{ }^{32}$ The key intuition is that if unemployment durations - which are a function of search intensity - are more responsive to unearned income than wages, local risk aversion must be high. Variation in unemployment insurance laws across states and time provide the needed variation in effective wages and unearned income.

Unlike in the case of global risk aversion, an analytical relationship between unemployment duration elasticities and the local curvature of utility cannot be obtained, because no closed-form solution exists for an unemployed agent's dynamic optimization problem. I therefore estimate local curvature using a structural job search model that accounts for dynamic behavioral responses. As the structural model involves several restrictive assumptions, I first build intuition for the identification strategy by describing the UI law variation and summarizing the reduced-form results of Chetty (2003b).

\subsubsection{Unemployment Insurance Laws}

Figure 2 illustrates the variation in UI laws by graphing potential benefit paths for three claimants earning $\$ 400$ per week in different states. The variation in these laws provides identification through two sources. ${ }^{33}$ First, weekly benefit levels vary significantly within the sample. Second, the path of benefits also varies: some states have a waiting week that must

\footnotetext{
${ }^{32}$ If some agents do abandon commitments during unemployment spells, the estimate of curvature using this method will be a lower bound for $\gamma^{l}$.

${ }^{33}$ The same variation in UI laws has previously been used to estimate the effects of unemployment benefit generosity on unemployment exit rates (Meyer, 1990), spousal labor supply (Cullen and Gruber, 2000), precautionary saving (Engen and Gruber, 1995), and consumption smoothing (Gruber, 1997).
} 
be served before benefits are received. In addition, among the states with waiting weeks, some have a "retroactive date" after which the payment for the waiting week is returned.

To identify local curvature, we must estimate the relative importance of income and price effects in determining the length of unemployment durations. This can be done in two ways. First, we can exploit variations in waiting weeks and retroactive dates. After the first week of unemployment has passed, claimants in states without waiting weeks have effectively received a temporary lump-sum grant relative to claimants in states with waiting weeks. By comparing unemployment exit rates in the two groups of states, we can identify the effect of unearned income on search behavior. ${ }^{34}$

The second method of decomposing the benefit elasticity is to exploit the finite duration of UI benefits. To see how this works, compare the search behavior of identical claimants earning $\$ 400$ in Massachusetts and California at several points during an unemployment spell. In MA, the claimant receives approximately $\$ 250$ per week for up to 26 weeks; in CA, he receives $\$ 150$ per week. Let us first focus on individuals who have already exhausted their UI benefits. Massachusetts residents who have exhausted their benefits have accumulated $\$ 2600$ more in benefits than their counterparts in California. Since there are no subsequent differences in UI payments, the higher UI benefits paid to those in MA can only affect search behavior after week 26 via the income effect. Now consider the week prior to benefit exhaustion. Here, higher UI benefits not only raise unearned income but also decrease the net-of-UI wage by $\$ 100$ in the next week. As a result, in week 25 , MA residents have less incentive to search not only because they have more unearned income, but also because

\footnotetext{
${ }^{34}$ It may be puzzling that a small change in UI benefits could have an income effect because the resulting change in lifetime income is trivial. The reason that temporary income fluctuations have an effect is that the unemployed tend to have very limited liquid assets and are likely to be credit constrained. For instance, Gruber (1997) shows that food consumption during unemployment is highly responsive to the level of UI benefits, confirming that small, transitory income variations do have substantial effects on behavior.
} 
they have a lower effective wage (net of UI benefits). Finally, consider the first week of an unemployment spell. At this point, MA residents have a lower effective wage for the next 26 weeks but have not yet accumulated more unearned income than those in CA. Higher UI benefits affect behavior primarily through the price channel at the beginning of the spell. Hence, if an increase in UI benefits reduces the hazard rate much more early in a spell than later in a spell, the price effect must be of greater importance than the income effect. But if higher UI benefits continue to reduce hazard rates late into an unemployment spell, income effects must be important and, based on the logic above, utility must be highly curved locally. ${ }^{35}$

It is important to observe that a standard loss aversion model does not predict a high value for $\gamma^{l}$ when it is estimated from variations in UI benefits. If the agent is loss averse and uses pre-unemployment consumption as a reference, the curvature of the value function is being estimated from variations in income that are strictly below his kink. In a more sophisticated model where the reference point moves along with the individual's consumption, the only way in which loss aversion itself could generate a high estimate of $\gamma^{l}$ is if we happen to "pass through" the kink at the reference when we vary income and estimate the change in marginal utility. However, there is obviously no positioning of one kink that could generate a high estimate of curvature between three or more unique points on the utility function. Since there are several UI benefit levels in the data, our estimate of $\gamma^{l}$ is effectively identified from observing changes in marginal utility across many different income levels. Consequently, this method would not yield a high estimate of $\gamma^{l}$ if agents were simply loss averse and commitments had no impact on risk preferences.

\footnotetext{
${ }^{35} \mathrm{~A}$ dynamic model of search is necessary because we need to take into account the fact that Michigan residents anticipate having higher unearned income while unemployed even at the beginning of the spell; using cumulative UI benefits as a measure of unearned income at a given point in the spell is therefore inappropriate.
} 


\subsubsection{Data}

The data used in this study are from the 1985-1987 and 1990-1996 panels of the Survey of Income and Program Participation. I make four exclusions on the original sample of job leavers to arrive at my final sample. First, following previous studies of UI, I restrict attention to prime-age males (over 18 and under 65). Second, I include only the set of individuals who report searching for a job at some point after losing their job, in order to eliminate individuals who have dropped out of the labor force from the analysis. Third, individuals who report that they were on temporary layoff at any point during their spells are dropped, since they might not have been actively searching for a job. Finally, I exclude individuals who have less than three months work history within the survey because there is insufficient information to estimate pre-unemployment wages for this group.

The core sample used in the analysis is the remaining set of 4,457 individuals who report receiving UI benefits in the month they became unemployed. I focus on individuals who take up UI within one month because I do not model the takeup decision, assuming instead that all individuals receive UI benefits upon unemployment. The model therefore applies most directly to those who actually begin receiving benefits shortly after unemployment. ${ }^{36}$ Since computational constraints limit the extent of heterogeneity that can be incorporated into the structural model, I use published state average benefits instead of each individual's actual UI benefit amount, assuming that there is a "representative agent" in each state/year pair. This limitation is likely to be inconsequential for the results, since reduced-form results are similar when each individual's simulated UI benefit level is used instead.

Table 2 gives summary statistics for the first-month UI claimants. The median UI

\footnotetext{
${ }^{36}$ Nonetheless, inclusion of the additional 2,409 UI recipients who do not take up UI in the first month does not affect the results.
} 
recipient is a high school graduate and has pre-UI gross annual earnings of $\$ 20,726$ in 1990 dollars. Most claimants have limited financial assets before their unemployment spells begin: median liquid wealth net of unsecured debt is only $\$ 186$. As in the general population, wealth inequality is extremely high in this group.

The mean weekly benefit amount is $\$ 168$, and there is considerable cross-state variation in unemployment benefits, from an average weekly benefit amount of $\$ 102$ in Louisiana to $\$ 217$ in Massachusetts in $19900^{37}$ Fifteen percent of the UI claimants began receiving benefits immediately upon unemployment (i.e. did not have a waiting week), while another $16 \%$ received a retroactive payment for the waiting week after their spell extended past a certain length (typically 4 weeks). Hence, there is a large amount of variation in the key aspects of the laws.

\subsubsection{Overview of Reduced-Form Results}

This section briefly reviews the results of Chetty (2003b), who estimates hazard models using the data described above to infer the relative magnitude of price and income effects in unemployment durations. The reduced-form approach serves two purposes. First, its transparency helps clarify the variation that is identifying the structural model. This should comfort readers who are concerned about the detailed assumptions required to estimate the search model. Second, the reduced-form evidence shows that the inclusion of covariates does not affect the estimates of the key income and price elasticities. This is reassuring because computational limits prevent the inclusion of many covariates in the structural estimation.

The key results can be summarized using graphs of Kaplan-Meier survival curves, which show the fraction of agents who remain unemployed $t$ weeks after job loss. Let us first divide

\footnotetext{
${ }^{37}$ Although some of this variation is due to differences in average wages across states, most of it is the result of differences in the UI laws themselves.
} 
states into two categories: those that have average weekly benefit amounts above the mean and those below the mean. Figure 3 shows that individuals who receive more benefits have a lower job-finding hazard rate throughout the spell, since the two survival curves do not begin to converge. ${ }^{38}$ Estimates of Cox survival models reveal that the coefficient on the interaction between weeks unemployed and the benefit rate is statistically and economically insignificant, indicating that UI benefits continue to reduce search effort even late in an unemployment spell. In addition, the interaction between the benefit exhaustion dummy and benefit rate is also insignificant, implying that UI continues to distort behavior even after benefits have ended. As emphasized above, these results indicate that UI affects search effort primarily via an income effect rather than a price effect. If the reduction in the net-of-UI wage were the primary source of changes in search behavior, higher benefits would reduce search effort much more at the beginning of a spell than in later weeks, and would have very little effect after benefits are exhausted.

Let us now divide states into two different categories: those that have a waiting week and no retroactive payment and those that have either no waiting week or make a retroactive payment for the waiting week at a later date. ${ }^{39}$ Claimants in the latter set of states (INC $=1$ ) get an extra week of benefits up front relative to claimants in the former group (INC $=0$ ). Note that the total weeks of benefits that both claimants can get remains the same; it is just that the individual in the INC $=1$ state has one week of benefits shifted from the end to the beginning. If income effects are important, this shift of income should have a short-lived but noticeable effect of the probability of survival. Figure 4 shows that this

\footnotetext{
${ }^{38}$ The hazard rate at week $t$ is the probability that a spell ends in week $t$ conditional on it lasting for at least $t$ periods. That is, $h_{t}=\operatorname{Pr}(d u r=t \mid d u r>=t)$.

${ }^{39}$ The states that make a retroactive payment for the waiting week are placed in the $I N C=1$ category because claimants in all of these states have an extra week of benefits after the retroactive date has passed. Of course, before the retroactive date, these claimants do not have a higher level of unearned income. This problem is resolved in the dynamic structural model estimated below.
} 
is indeed the case: Individuals in the INC $=1$ states have significantly lower job-finding hazards in the first two months after unemployment, but begin to catch up to the other states in subsequent weeks. Correspondingly, the hazard model estimates indicate that the hazard rates of the INC $=1$ group defined above are noticeably lower in the first two months and higher in the third month of unemployment. The fact that a small lump-sum grant has non-trivial effects on search behavior again points to the importance of income effects for these committed agents, which as noted above implies high $\gamma^{l}$.

All of the preceding results are robust to the inclusion of controls such as a ten-piece spline for wage, age, education, marital status, the state unemployment rate, and industry, occupation, year, and month dummies. In addition, the inclusion of state fixed effects does not affect the results.

Under the restrictive assumption that agents choose search effort in each month of their unemployment spell without considering implications for future consumption or employment (e.g., because of binding credit constraints), Chetty (2003b) shows that these reduced-form estimates imply $\gamma^{l}=8$. Before proceeding to estimate $\gamma^{l}$ in a more general setting using a dynamic search model, I address two potential biases that could potentially affect the analysis. First, is the variation in UI laws across states and time correlated with unobserved heterogeneity that affects unemployment durations? One way of confirming that the UI laws are causal is to check whether the income and price effects do not emerge for individuals who do not get UI. Indeed, the point estimates for this "control" group are close to zero, and the $95 \%$ confidence intervals do not include the point estimates of the income and benefits elasticities for the UI claimants.

Second, is there selection with respect to the UI law? Evidence from Chetty (2003b) suggests that selection bias is minor, and if at all works against finding a high estimate 
of local curvature. Waiting periods have no effect on UI takeup rates, and selection with respect to the level of UI benefits is sufficiently small that any bias in the estimated hazard rates is dwarfed by the standard errors. A deeper concern is that selection occurs over the unemployment spell, i.e., the pool of agents who remain unemployed after several weeks is different in states with low vs. high UI benefits. Fortunately, selection bias of this type is likely to work against finding an estimate of high local curvature. Higher-skilled agents are more likely to remain unemployed for a long time in high-benefit states relative to low benefit states. Since more skilled agents have higher unemployment exit hazards, this selection effect should push the hazards in high-benefit states up relative to the hazards in low-benefit states as the spell elapses. This effect makes us understate the extent to which UI benefits reduce hazard rates late in an unemployment spell. Based on our identification strategy for the income effect, it follows that this would only cause us to underestimate the size of the income effect relative to the price effect, and thereby underestimate local curvature.

\section{Structural Estimation of Local Risk Aversion}

\subsection{Dynamic Search Model}

The structural estimation procedure implemented below involves three steps: (1) compute each agent's optimal unemployment exit hazards using a search model, given the UI law he faces and a set of core preference parameters, $\omega$ that includes the key $\gamma^{l}$ parameter; (2) use these hazards to compute the likelihood of observing a given set of unemployment durations for a given value of $\omega$; and (3) estimate $\omega$ by maximizing the likelihood function. ${ }^{40}$

\footnotetext{
${ }^{40}$ Several studies have estimated structural parameters of job search models. Wolpin (1987) structurally estimates parameters of the wage offer distribution and the reservation wage. More recently, Paserman (2002) estimates hyperbolic preference parameters for unemployed agents. Existing structural models assume
} 
In canonical job search models, agents either choose a reservation wage or search effort in each period. ${ }^{41}$ I adopt the latter strategy primarily because it reduces the computational intensity of the search problem in a manner that will be made clear shortly. This assumption does have some empirical basis: Wolpin (1987) and van den Berg (1990) find that reservation wages are very low and that job offers are accepted with a probability close to 1 . This suggests that the primary disincentive effects of UI occur through a reduction of search intensity for job offers, rather than rejection of a larger fraction of offers after they are obtained.

I first outline the main features of the model, postponing discussion of the specific parametric assumptions that are made until the next section. I consider a discrete-time setting in which each period corresponds to one week, since unemployment duration data is available only at a weekly frequency. All dates that follow refer to time elapsed since the beginning of an unemployment spell and not to calendar time.

(a) Consumption. The agent has an infinite horizon and becomes unemployed exogenously with initial assets $a_{0}$ at time 0 . Following a job separation, in each week $t$, he chooses food consumption, $f_{t}$, and housing consumption, $h_{t}$. Assume that agents do not abandon their commitments while searching for a new job. This simplifies the consumption decision to choosing $f_{t}$ in each period. ${ }^{42}$ Since $h_{t}$ is fixed at $\bar{h}$ throughout the search process, the housing argument of agent's utility is suppressed and utility is denoted by $u\left(f_{t}\right)$ when the meaning is not ambiguous. The key parameter to be estimated is the curvature $\gamma_{f}=\frac{-u_{f f}}{u_{f}} f$,

a linear utility function and therefore do not identify the curvature of utility. The introduction of a curved utility greatly complicates the estimation procedure because it makes the search problem analytically intractable.

${ }^{41}$ Lippman and McCall (1979) and Atkinson and Micklewright (1991) reviews the theory and empirics of the job search literature.

${ }^{42}$ As noted above, if some agents do move out of their houses during unemployment spells, the estimate of local curvature will be biased downward. 
which can be translated into $\gamma^{l}$ using (3).

The agent has a time discount factor $\beta$ and savings earn a net interest rate $r=\frac{1}{\beta}-1$. I model credit constraints by assuming that the agent can borrow up to a fixed amount $\bar{B}$. Letting $b_{t}$ denote unemployment benefits in week $t$ of the spell, the worker's intertemporal budget constraint is

$$
a_{t+1}=(1+r)\left(a_{t}+b_{t}-\bar{h}-f_{t}\right)
$$

The $\left\{b_{t}\right\}$ paths are heterogeneous across agents; it is the variation in UI benefit paths that allows us to estimate the agent's utility function.

(b) Job Search. While unemployed, the agent chooses a level of search effort $e_{t}$ in each week to find a new job. Once the agent finds a job, it is permanent, and pays a wage of $w$ per week. The disutility of working is denoted by $\psi$.

Higher search effort translates directly into a higher probability of finding a job: the probability of finding a job in period $t$ is

$$
p_{t}=\alpha_{t} e_{t}
$$

The $\alpha_{t}$ parameters can be interpreted as the "baseline" probabilities of finding a job in week $t$ of an unemployment spell when one exerts 1 unit of search effort. These parameters are allowed to vary over time to capture the fluctuations in unemployment exit hazards over time. In addition, the $\alpha_{t}$ parameters depend on local economic conditions, as reflected by the state unemployment rate when an individual loses his job.

Search is costly: the agent incurs a disutility of $c(e)$ by expending $e$ units of search effort. Assume that $c$ is twice differentiable and convex.

Since our estimates of local curvature are identified by variations in short-run search be- 
havior, a finite search horizon of $T=55$ weeks is imposed on the model. This is a reasonable assumption since job finding hazards are quite low after one year of unemployment in practice. If an individual reaches week $T+1$ without finding a job, he receives a fixed welfare payment for the remainder of his life. In addition, I assume that the agent abandons his commitments in week $T+1$, reoptimizing and choosing a new value of housing consumption after this point. Since the agent's problem is stationary after week $T$, a closed-form solution for the value function at $T+1$ can be obtained.

(c) Agent Optimization. The agent's problem can be solved using dynamic programming. There are two state variables: assets and the employment state.

I first characterize optimal behavior in the employed state, where the agent faces a stationary eat-the-pie problem without uncertainty. This problem has a simple solution: the agent consumes a constant fraction of his lifetime wealth in all subsequent periods. If the agent has assets $a_{t}$ and begins working in week $t$, he consumes

$$
f_{t}^{e}=r a_{t}+w-\bar{h}
$$

per week for the rest of his life. This implies that the agent's value function when employed is the present value of his lifetime utility:

$$
V_{t}^{e}\left(a_{t}\right)=\frac{1}{1-\beta}\left\{u\left(r a_{t}+w-\bar{h}\right)-\psi\right\}
$$

Let us now analyze the unemployed state. While unemployed, the value function in periods $t \in\{1, \ldots, T\}$ is

$$
V_{t}^{u}\left(a_{t}\right)=\sup _{f_{t}, e_{t}} u\left(f_{t}\right)-c\left(e_{t}\right)+\beta\left\{\alpha_{t} e_{t} V_{t+1}^{e}\left(a_{t+1}\right)+\left(1-\alpha_{t} e_{t}\right) V_{t+1}^{u}\left(a_{t+1}\right)\right\}
$$


When utility is nonlinear, the Bellman equation in (14) does not have an analytical solution. Given functional form assumptions on $u$ and $c$, the sequence $\left\{V_{t}^{u}\left(a_{t}\right)\right\}_{t=1}^{T}$ can be obtained by starting with the value function in the terminal period, $V_{T+1}\left(a_{T+1}\right)$, and using numerical backwards induction to solve the system in (14). The terminal value function $V_{T+1}\left(a_{T+1}\right)$, which gives the value of going on welfare with assets $a_{T+1}$, can be computed as follows. First, observe that in week $T+1$, the agent faces another stationary eat-the-pie consumption problem, and again consumes a constant fraction of his wealth for the remainder of his life. By assumption the agent will sell his house and incur the fixed transaction cost. Let $\underline{w}$ denote the agent's weekly welfare payment net of (annuitized) transaction costs after period $T$. Optimal housing consumption after this point, $h_{\underline{w}}$, can be computed by solving a static utility maximization problem numerically. It follows that the value function in week $T+1$ is

$$
V_{T+1}^{u}\left(a_{T+1}\right)=\frac{1}{1-\beta} u\left(h_{\underline{w}}\left(a_{T+1}\right), \underline{w}-h_{\underline{w}}\left(a_{T+1}\right)\right)
$$

Given $V_{T+1}$, solving the dynamic programming problem requires optimization over both effort and consumption in each week $t$ for every level of assets $a_{t}$ with which one could enter week $t$. This two-dimensional optimization problem can be reduced to a one-dimensional search for the optimal consumption path when unemployed, $\left\{f_{t}^{u}\right\}$, by deriving an analytic expression for $e_{t}\left(a_{t}\right)$ in terms of $f_{t}^{u}$ and the value functions at time $t+1, V_{t+1}^{e}\left(a_{t+1}\right)$ and $V_{t+1}^{u}\left(a_{t+1}\right)$. Since $c(e)$ is convex, $V_{t}^{u}\left(a_{t}\right)$ is concave in $e_{t}$ and the optimal effort level is given by the first order condition

$$
c^{\prime}\left(e_{t}\right)=\beta\left[V_{t+1}^{e}\left(a_{t+1}\right)-V_{t+1}^{u}\left(a_{t+1}\right)\right] \alpha_{t}
$$

By choosing a tractable functional form for $c(e)$, we can directly calculate the optimal effort 
level at time $t$ for a given level of $a_{t}$ and $f_{t}$, after we have computed the value functions at time $t+1$. This analytic simplification tremendously increases the speed of the algorithm, and is the benefit of formulating the model in terms of search effort rather than reservation wages.

The core parameters and functions required to solve the problem are

$$
\omega=\left\{u, c,\left\{\alpha_{t}\right\}_{t=1}^{T-1}, \psi, \beta\right\}
$$

Given values of $\left\{w, \underline{w}, \bar{B}, \bar{h},\left\{b_{t}\right\}_{t=1}^{T-1}\right\}$ and the initial asset level $a_{0}$, solving the dynamic programming problem yields an optimal policy $\left\{f_{t}^{u}, f_{t}^{e}, e_{t}\right\}_{t=1}^{T-1}$ for an agent in terms of the core parameters $\omega$. Indexing the individuals in the sample by $i=1, \ldots, I$, we can solve the model $I$ times to obtain an optimal search effort path $\left\{e_{t}^{i}\right\}_{t=1}^{T-1}$ for each agent. The $i^{t h}$ agent's unemployment exit probabilities are

$$
p_{t}^{i}=\alpha_{t}^{i} e_{t}^{i}
$$

(d) Likelihood Function. ${ }^{43}$ The likelihood of observing a given dataset of unemployment durations for a core parameter vector $\omega$ can be directly computed from the exit probabilities that come out of the search model. Suppose individual $i$ has an unemployment duration of $d_{i}$ weeks. The probability of this event is the product of the probability that the individual does not find a job in weeks 1 to $d_{i}$ and the probability that he finds a job in week $d_{i}+1$ :

$$
\operatorname{Pr}\left(d_{i} ; \omega\right)=\prod_{t=1}^{d_{i}}\left(1-p_{t}^{i}(\omega)\right) p_{d_{i}+1}^{i}(\omega)
$$

Suppose the first $I_{1}$ individuals have uncensored spells and the remaining $I_{2}$ individuals have

\footnotetext{
${ }^{43}$ Kiefer (1988) provides a review of maximum likelihood estimation of survival models.
} 
spells that are right-censored at $d_{i}$. The likelihood function is

$$
L(\omega)=\prod_{i=1}^{I_{1}+I_{2}} \prod_{t=1}^{d_{i}}\left(1-p_{t}^{i}(\omega)\right) \prod_{i=1}^{I_{1}} p_{d_{i}+1}^{i}(\omega)
$$

The structural parameters of the search model, including local curvature, can be estimated by maximizing the likelihood in (17) if one can observe true unemployment durations. Unfortunately, this is not possible in practice: There is an important mismeasurement problem in the SIPP data known as the "seam effect." To see how this reporting problem emerges, note that the data is collected by interviewing individuals every four months about their activities during the past four months, which is termed the "reference period." Individuals tend to repeat answers about weekly job status. As a result, the probability of reporting a transition to employment is six times larger on the seam than within reference periods. Consequently, many spells of unemployment appear to last for exactly the length of one or two reference periods, which correspond to lengths of 17 and 35 weeks.

To account for this mismeasurement problem, I test the robustness of the results by explicitly modelling and estimating the process that generates the reporting errors. In particular, I consider a mixture model with two types of individuals: exact reporters, who always report the truth, and seam reporters, who always report job-finding on the nearest seam. I then estimate the fraction of seam reporters, $\mu$, along with the core parameters of the search model. It turns out that the estimate of local curvature is unaffected by this correction for measurement error. A full description of the model of recall errors is given in the appendix. 


\subsection{Estimation Details}

I choose the following functional form for utility over consumption:

$$
u(h, f)=\frac{f^{1-\gamma_{f}}}{1-\gamma_{f}}+\eta \frac{h^{1-\gamma_{h}}}{1-\gamma_{h}}
$$

The key parameter for our analysis is $\gamma_{f}$. The nuisance parameters $\gamma_{h}$ (curvature of utility over housing) and $\eta$ (relative weight placed on housing in utility) cannot be identified from data on unemployment durations. However, these two parameters can be expressed in terms of $\gamma_{f}, \bar{h}$, and the global coefficient of relative risk aversion $\gamma^{g}=1$ estimated in Chetty (2003a). In other words, $\left\{\gamma_{f}, \eta, \gamma_{h}\right\}$ is homeomorphic to $\left\{\gamma_{f}, \bar{h}, \gamma^{g}\right\}$. Since both $\gamma^{l}(W)$ and $\gamma^{g}(W)$ vary with $W$ under this specification of $u(h, f)$, I will assume that $\gamma^{g}\left(W_{0}\right)=1$ at the

agent's pre-unemployment wealth $W_{0}$ and report estimates of $\gamma^{l}\left(W_{0}\right)$ at the same point for comparison.

I also assume a power specification for the cost of effort:

$$
c(e)=[u(\bar{h}, w-\bar{h})-u(\bar{h}, w-\bar{h}-150)] \frac{e^{\theta}}{\theta}
$$

This parametrization assumes that the elasticity of cost of effort with respect to effort is constant: $\varepsilon_{c, e}=\theta$. The multiplicative scalar $[u(\bar{h}, w)-u(\bar{h}, w-150)]$ is included to aid in the interpretation of the estimates of the baseline job-finding probabilities $\left\{\alpha_{t}\right\}_{t=1}^{T-1}$. With this choice of units, the cost of one unit of effort is normalized as the welfare cost of losing $\$ 150$ of food per week.

Similarly, to aid in the interpretation of the disutility of labor parameter $\psi$, I define

$$
\psi=u(\bar{h}, w-\bar{h})-u\left(\bar{h}, w-\bar{h}-\psi_{\S}\right)
$$


and report the estimate of $\psi_{\$}$, which can be interpreted as the disutility of labor expressed in dollars of food consumption lost from the initial level.

To reduce the parameter set, I replace the nonparametric specification of the baseline job-finding probabilities $\left\{\alpha_{t}\right\}_{t=1}^{T-1}$ with a piecewise linear functional form. Monthly break points are included in the linear spline for the $\alpha$ parameters for the first five months and breaks every two months are included for the remainder of the search horizon:

$$
S=\{1,5,9,13,17,25,32,40,48,55\}
$$

I include more breaks early in the spell since weekly fluctuations in job search productivity are likely to diminish as a spell wears on. The values of $\alpha_{t}$ in the other weeks are obtained by linearly interpolating between the break points. I check that the specification of $\left\{\alpha_{t}\right\}$ is sufficiently flexible by showing that the inclusion of additional pieces in the linear spline (expansion of $S$ ) does not affect the estimates of the key parameters.

The scale of the $\alpha_{t}$ parameters depends on the state unemployment rate when individual $i$ loses his job, allowing us to control for local economic conditions:

$$
\alpha_{t}^{i}=\alpha_{t}\left(1+\alpha_{u} \text { unempdev }^{i}\right)
$$

where unempdev ${ }^{i}$ denotes the deviation in the state unemployment rate when agent $i$ becomes unemployed from the overall mean in the sample.

With this notation, the set of parameters to be estimated in the structural model is reduced to:

$$
\widetilde{\omega}=\left\{\gamma_{f}, \theta, \psi_{\S},\left\{\alpha_{t}\right\}_{t \in S}, a_{u}\right\}
$$


The remaining parameters $\{\bar{h}, \underline{w}, \bar{B}, \beta\}$ are specified exogenously. The estimation algorithm is run for different values of these parameters to check sensitivity. Since CPU time increases linearly in the number of dynamic programming problems solved, I eliminate individual heterogeneity and estimate a representative agent model in which each agent earns the mean wage in the sample gets the mean weekly benefit amount for his (state,year) pair. As noted above, the reduced-form estimates remain similar when individual benefits are replaced with state-year averages, justifying this simplification.

\subsection{Parameter Estimates}

Table 3 reports estimates of the search model. I begin by discussing a benchmark specification in detail, and then turn to robustness checks. In specification (1), which includes the measurement-error correction, the weekly wage is fixed at the sample mean $w=400$. I assume that agents have committed $\bar{h}=200$ of their budgets to housing prior to unemployment, and that they have pre-unemployment assets of $a=500$. I fix $\beta=0.9^{1 / 50}$ to reflect a yearly discount rate of $10 \%$. The welfare payment after week 55 is set at $\underline{w}=100$. These values are roughly in correspondence with the average values in the data and prior empirical estimates.

It is more difficult to specify the borrowing constraint because of the lack of data on this parameter. Intuitively, $\bar{B}$ reflects both the ability to make late payments on the commitments and actual borrowing channels such as credit cards. To gauge the direction of the bias from misspecification of $\bar{B}$, note that a lower level of $\bar{B}$ raises the percentage change in consumption associated with an increase in UI benefits, $\frac{\Delta f}{f}$. If the agent faced very tight borrowing constraints, an extra dollar of UI would be used to raise consumption rather than to reduce borrowing. Next, observe that the change in search effort in response 
to a change in unearned income depends on the product of $\gamma^{l}$ with $\frac{\Delta f}{f}$ - the larger the drop in consumption, the more the incentive to start searching harder. Generating a search effort response of a given magnitude with a larger $\frac{\Delta f}{f}$ requires a smaller $\gamma^{l}$. Hence, underestimating $\bar{B}$ will bias us toward overestimating $\frac{\Delta f}{f}$ and underestimating $\gamma^{l}$, making it harder to find evidence in favor of the model.

We can evaluate whether $\bar{B}$ is underestimated by checking if the mean consumption drop generated by the model is larger than what is observed empirically. If the predicted drop is larger than the observed, the borrowing constraint in the model must be tighter than what unemployed individuals actually face. Gruber (1997) estimates that the average drop in food consumption is $10 \%$ at the mean UI benefit level. I therefore try to err on the conservative side and set $\bar{B}=11,000$ in the benchmark specification, which implies an average food consumption drop of approximately $20 \%$ during unemployment. ${ }^{44}$

Given these values for the exogenous parameters, the maximum likelihood estimate of the key local curvature parameter, $\gamma^{l}$, is 7.37 and the standard error is $2.07 .^{45}$ We can confidently reject the null hypothesis that commitments do not affect the curvature of utility $\left(\gamma^{l}=\gamma^{g}<1.25\right)$

The estimates of the other parameters in the model appear reasonable. The estimate of $\theta=\varepsilon_{c, e}=1.54$ indicates that a $10 \%$ increase in effort results in a $15 \%$ increase in the disutility of search. The disutility of labor is estimated as equivalent to losing $\$ 72.50$ of food consumption per week starting at an initial value of $\$ 200$. The estimates of the baseline job finding probabilities show that exerting one unit of search effort, which costs the equivalent

\footnotetext{
${ }^{44}$ Since the likelihood in (17) is only a function of unemployment durations, this consumption data cannot be used to estimate $\bar{B}$ within the maximum likelihood procedure.

${ }^{45}$ Standard errors are obtained by inverting a maximum likelihood ratio test, i.e. constructing an interval such that the null hypothesis that the parameter lies outside this interval can be rejected with a given $\mathrm{p}$ value. The more common method of inverting the asymptotic information matrix could not be applied here because of problems in computing second derivatives numerically.
} 
of losing $\$ 150$ of food, results in a 3-4\% chance of finding a job in each week during the first six months after unemployment. Since losing $\$ 150$ of food has significant welfare costs, these estimates suggest that the job search process is quite unpleasant. The estimate of $\alpha_{u}$ indicates that a 1 percentage point increase in the state unemployment rate lowers the job finding hazard by approximately $5 \%$. It is reassuring that the structural estimate of the state unemployment rate coefficient almost exactly matches the reduced-form estimate of this coefficient reported in Chetty (2003b). Finally, the estimate of $\mu=0.33$ indicates that approximately one third of the individuals in the sample are seam reporters who do not accurately report job transitions within a reference period.

I now turn to the results of some sensitivity checks. In specification (2), I estimate the model without including the measurement error correction by maximizing the likelihood for true durations in (17). The point estimate of $\gamma^{l}$ remains similar, but the standard error of the estimate rises. The bunching of unemployment durations at 17 weeks is picked up by the spike in the baseline hazard in week $17\left(\alpha_{17}\right)$. Specification (3) replicates specification (1) but reduces the number of break points in the specification of the baseline hazards. The estimate of $\gamma^{l}$ remains virtually unchanged. This suggests that the specification of the baseline job-finding probabilities is sufficiently flexible that the key curvature parameter is being identified only from cross-sectional variations and not the overall time-pattern of unemployment exit rates. Finally, in specification (4), I check the sensitivity of $\gamma^{l}$ to the value of the borrowing constraint by setting $\bar{B}=10,000$. As expected, this lowers the estimate of $\gamma^{l}$, but the new point estimate of 6.15 lies well within the $95 \%$ confidence interval for the estimate in the benchmark specification.

Is the estimate of $\gamma^{l}$ being identified from the variation in income and price effects created by the UI laws, as described above? Figure 5 uses the estimates of specification (2) to plot 
predicted survival curves for individuals in states that pay UI benefits below the mean and those that pay UI benefits above the mean. The empirical survival curves for these two categories are also shown. ${ }^{46}$ Visual assessment of the fit indicates that the model captures both the time pattern of unemployment exit rates and the cross-sectional variation due to UI laws quite well. For comparison, Figure 6 replicates Figure 5 when $\gamma^{l}$ is held fixed at 2.5 while the likelihood function is maximized over all the other parameters. The predicted survival curves using these restricted maximum likelihood estimates continue to fit the overall time pattern of unemployment exit rates well; however, they fail to capture the extent to which higher UI benefits diminish search intensity late in the spell (the gap between the two curves). Together, these two figures indicate that $\gamma^{l}$ is being identified from precisely the variation in UI laws that one would expect based on the intuition given above. The fact that higher UI benefits persistently reduce unemployment exit rates throughout an unemployment spell, even after benefits have been exhausted, can only be explained by a high value of $\gamma^{l}$ in the dynamic search model.

Figure 7 summarizes the empirical content of the commitments model by plotting utility over wealth for a model without credit constraints in which the agent faces no uncertainty after the current period. The figure assumes $\gamma^{l}\left(W_{0}\right)=7.37$ at the agent's initial wealth level $W_{0}$. In this example, the agent has an annual income of $\$ 40,000$, a prior commitment of $50 \%$ of income, and faces an adjustment cost of $7.5 \%$. Assuming a $5 \%$ interest rate and an infinite horizon, this agent's initial lifetime wealth is $W_{0}=\$ 800,000$. The committed region within the $(s, S)$ band includes roughly $\pm 10 \%$ of lifetime wealth. Commitments have a significant effect on risk preferences: Utility is considerably more curved locally than

\footnotetext{
${ }^{46}$ I plot predicted survival curves for specification (2) rather than (1) because generating predictions from the measurement error model requires that we re-create the measurement error in the empirical survival curves. This is difficult because we need to take the actual distribution of seams in the population into account.
} 
it is globally, as shown by the dashed curve, which extends the utility function within the committed region outside the $(s, S)$ band.

\section{Implications of Commitments}

This paper has characterized preferences over wealth in a world with two consumption goods, one of which involves a commitment in that an adjustment cost must be paid when the good is sold. In this model, utility over wealth is more curved locally than globally: individuals are relatively more risk averse with respect to moderate-scale income fluctuations than they are to large income fluctuations. Commitments also create a gambling motive.

The model was tested and calibrated using the labor-supply method of estimating risk aversion developed in Chetty (2003a). Existing estimates of wage and income elasticities from the static labor supply literature imply an upper bound for global curvature of 1.25. Differences in unemployment insurance laws across states and time allow us estimate the local curvature of utility. Reduced-form estimates of semiparametric hazard models and structural estimates of a dynamic job search model reveal that the local coefficient of relative risk aversion is around 7 . The empirical estimate of the difference between local and global curvature comes from two facts about labor supply: (1) Permanent increases in income do not reduce labor supply significantly, implying that the taste for consumption deteriorates

slowly with wealth; but (2) temporary fluctuations in income do cause large labor supply responses, indicating that the marginal utility of wealth falls rapidly when substitution across consumption goods is hindered by prior commitments.

I conclude by discussing a few empirical puzzles that commitments could help explain:

1. [Risk Aversion and Insurance] Retaining a consequentalist, expected utility framework, 
the commitments model escapes Rabin's (1999) critique by generating a utility that is not everywhere concave. The utility in Figure 7 rejects the $50-50 \$ 1000 / \$ 1050$ bet but accepts the $\$ 40000 / \$ 6.35$ million one. It also rationalizes the desire to insure moderate-scale shocks through automobile and non-catastrophic health insurance.

2. [Gambling] The model explains why racetrack bettors prefer bets with long odds and large payoffs (Golec and Tamarkin, 1998). It is also consistent with the finding that higher incomes are less likely to play the lottery overall, but are relatively more likely to participate in lotteries that have very large payoffs (Clotfelter and Cook, 1987).

3. [Intertemporal Substitution] Commitments can reconcile limited intertemporal substitution, non-ridiculous degrees of risk aversion over large stakes, and time-separability of utility. When utility is time-separable, the elasticity of intertemporal substitution is the reciprocal of the curvature of utility over wealth. A large fraction of intertemporal substitution among nondurables and services is likely to occur while individuals are maintaining commitments. Since the relevant curvature parameter for intertemporal substitution lies between $\gamma^{g}=1$ and $\gamma^{l} \approx 7$ in this case, an EIS significantly below 1 (as estimated e.g., by Hall (1988), Epstein-Zin (1991), and Vissing-Jorgensen (2002)) would be consistent with the risk preferences of committed agents.

4. [Wage Rigidities] Committed individuals may prefer a gamble in which they get fired with a small probability rather than take a reduction in wages with certainty. Hence, the model can explain workers' disdain for small wage cuts, and why firms are reluctant to cut wages and instead choose to lay off workers, as discussed e.g., in Bewley (1999).

5. [Labor Supply] Mincer (1962) and Cullen and Gruber (2000) document a large "added worker" effect: Spouses enter the labor force when primary earners become unem- 
ployed. Commitments rationalize this behavior by making labor supply relatively more responsive to transitory income fluctuations than permanent ones.

6. [Taxation] Studies of the labor supply response to taxation find very small tax elasticities for households with incomes below $\$ 100,000$ (see e.g., Gruber and Saez (2000). The inability to fully reoptimize consumption in the short run may dampen responses to tax reforms even if taxes are highly distortionary in the long run.

7. [Crime and Punishment] Becker (1968) showed that the optimal punishment strategy for risk averse agents combines large fines with low probabilities of punishment. However, empirical evidence indicates that extensive resources are in fact devoted to enforcement (see e.g. Dickens et. al. (1989), who label this a "monitoring puzzle"). Criminals with commitments may be more sensitive to the probability of apprehension than to the severity of the punishment.

8. [Asset Pricing] Chetty and Szeidl (2003) aggregate a model of commitments and show that when calibrated appropriately, it can explain the equity premium puzzle - why stocks have historically had a high rate of return despite their low covariance with consumption. Moreover, they find that an exogenous increase in housing commitments causes a large portfolio reallocation from stocks to bonds, as the model predicts.

9. [Optimal Unemployment Insurance] The answer to the applied question that motivated this paper - What is the optimal level of social insurance? - changes significantly when commitments are taken into account. Using the same parameters as those in Gruber (1997), the optimal replacement rate for pre-unemployment wages rises from 0 to 0.44 when commitments are incorporated into the model with the empirical utility over 
wealth estimated above. ${ }^{47}$ The optimal replacement rate for long-term shocks such as disability may be much lower, insofar as all types of consumption get adjusted in the long run.

\footnotetext{
${ }^{47}$ From a positive standpoint, it is interesting to note that commitments appear to be the motivation for UI. In the Arizona State Benefit Adequacy Study, Burgess et. al. (1981) define a measure of "benefit adequacy." They emphasize that "this measure of benefit adequacy is defined for each beneficiary within the context of his/her household circumstances. These circumstances are reflected by the total of necessary/obligated expenses for the entire household...."
} 


\section{References}

Atkinson, Anthony. and John Micklewright, "Unemployment Compensation and Labor Transitions: A Critical Review," Journal of Economic Literature 29 (1991), 1679-1727.

Attanasio, Orazio, "Consumer Durables and Inertial Behavior: Estimation and Aggregation of Ss Rules for Automobiles," Review of Economic Studies 67 (2000), 667-696.

Baily, Martin, "Some Aspects of Optimal Unemployment Insurance," Journal of Public Economics 10 (1978), 379-402.

Becker, Gary, "Crime and Punishment: An Economic Approach," Journal of Political Economy 76 (1968), 169-217.

Becker, Gary, Kevin Murphy, and Iván Werning, "Status, Lotteries and Inequality," University of Chicago mimeo (2000).

Bewley, Truman. Why Wages Don't Fall During a Recession, Cambridge: Harvard University Press (1999).

Brunnermeier, Markus, "On Bounded Rationality and Risk Aversion," LSE Financial Markets Group Discussion Paper 255 (1997).

Burgess, Paul, Jerry Kingston, Robert St. Louis, and Joseph Sloan, "Changes in Spending Patterns Following Unemployment," U.S. Department of Labor Employment and Training Administration Occasional Paper 81-3, Washington D.C. (1981).

Camerer, Colin, "Recent Tests of Generalized Utility Theories," in Utility Theories: Measurement and Applications, ed. Ward Edwards. Cambridge: Cambridge University Press (1992).

Clotfelter, Charles and Phillip Cook, "Implicit Taxation in Lottery Finance," National Tax Journal (1987), 533-547.

Chetty, Raj, "A New Method of Estimating Risk Aversion," NBER Working Paper 9988 (2003a).

Chetty, Raj, "Optimal Unemployment Insurance When Income Effects are Large," UCBerkeley mimeo (2003b).

Chetty, Raj and Adam Szeidl, "Consumption Commitments and Asset Prices," Harvard University mimeo (2003).

Cullen, Julie and Jonathan Gruber, "Does Unemployment Insurance Crowd Out Spousal Labor Supply?" Journal of Labor Economics 18 (2000), 546-572.

Dickens, William, Lawrence Katz, Kevin Lang, and Lawrence Summers, "Employee Crime and the Monitoring Puzzle," Journal of Labor Economics 7 (1989), 331-347.

Engen, Eric and Jonathan Gruber, "Unemployment Insurance and Precautionary Savings." National Bureau of Economic Research Working Paper No. 5252 (1995).

Epstein, Larry and Stanley Zin, "Substitution, Risk Aversion, and the Temporal Behavior of Consumption and Asset Returns: An Empirical Analysis," Journal of Political Economy 99 (1991), 263-286. 
Ferreira, Fernando. "You Can Take It with You: Transferability of Proposition 13 Tax Benefits, Residential Mobility, and Willingness to Pay for Housing Amenities," UC-Berkeley mimeo (2003).

Flavin, Marjorie and Shinobu Nakagawa, "A Model of Housing in the Presence of Adjustment Costs: A Structural Interpretation of Habit Persistence," University of California, San Diego mimeo (2003).

Flemming, J.S., "The Utility of Wealth and the Utility of Windfalls," The Review of Economic Studies 36 (1969), 55-66.

Friedman, Milton and L.J. Savage, "The Utility Analysis of Choices Involving Risk," Journal of Political Economy 56 (1948), 279-304.

Glaeser, Edward and Jesse Shapiro, "The Benefits of the Home Mortgage Interest Deduction," National Bureau of Economic Research Working Paper No. 9284 (2002).

Golec, Joseph and Maurry Tamarkin, "Betters Love Skewness, Not Risk, at the Horse Track" Journal of Political Economy 106 (1998), 205-225.

Grossman, Sanford J. and Guy Laroque, "'Asset Pricing and Optimal Portfolio Choice in the Presence of Illiquid Durable Consumption Goods," Econometrica 58 (1990), 25-52.

Gruber, Jonathan, "The Consumption Smoothing Benefits of Unemployment Insurance," American Economic Review 87 (1997), 192-205.

Gruber, Jonathan, "Unemployment Insurance, Consumption Smoothing, and Private Insurance: Evidence from the PSID and CEX," Research in Employment Policy 1 (1998), 3-31.

Hall, Robert, "Intertemporal Substitution in Consumption," Journal of Political Economy 96 (1988), 339-357.

Hartley, Roger and Lisa Farrell, "Can Expected Utility Theory Explain Gambling?" American Economic Review 92 (2002), 613-624.

Kahneman, Daniel and Amos Tversky, "Prospect Theory: An Analysis of Decision under Risk," Econometrica 47 (1979), 263-292.

Kaplan, E.L. and Meier, P, "Nonparametric Estimation for Incomplete Observations," Journal of the American Statistical Association 53, 457-481.

Kiefer, Nicholas, "Economic Duration Data and Hazard Functions," Journal of Economic Literature 26 (1988), 646-79.

Kwang, Ng, "Why do People Buy Lottery Tickets? Choices Involving Risk and the Indivisibility of Expenditure," Journal of Political Economy 73 (1965), 530-535.

Lippman, Steven and John McCall, Studies in the Economics of Job Search, Amsterdam: North Holland (1979).

Machina, Mark, "Choice Under Uncertainty: Problems Solved and Unsolved," Journal of Economic Perspectives 1 (1987), 121-154.

Martin, Robert, "Bonsumption, Durable Goods, and Transaction Costs," FRB International Finance Discussion Papers No. 756 (2003). 
Meyer, Bruce D., "Unemployment Insurance and Unemployment Spells," Econometrica, Volume 58, Issue 4 (Jul., 1990), 757-782.

Mincer, Jacob "Labor Force Participation of Married Women," in Aspects of Labor Economics. National Bureau of Economic Research (1962).

Paserman, Daniele "Job Search and Hyperbolic Discounting: Structural Estimation and Policy Implications," Manuscript, Hebrew University of Jerusalem (2002).

Rabin, Matthew, "Risk Aversion and Expected-Utility Theory: A Calibration Theorem." Econometrica 68 (2000), 1281-1292.

Scarf, Herbert, "The Optimality of (s,S) Policies in the Dynamic Inventory Problem" in Mathematical Methods in the Social Sciences: Proceedings of the First Stanford Symposium, Stanford University Press (1959).

van den Berg, Gerard, "Search Behaviour, Transitions to Non-Participation, and the Duration of Unemployment," Economic Journal 100 (1990), 842-865.

Vissing-Jorgensen, Annette, "Limited Asset Market Participation and the Elasticity of Intertemporal Substitution," Journal of Political Economy 110 (2002), 825-853.

Wolpin, Kenneth I., "Estimating a Structural Search Model: The Transition from School to Work," Econometrica, Volume 55, Issue 4 (Jul. 1987), 801-817. 


\section{Appendix A: Derivation of (9)}

It was previously established that

$$
\frac{\partial \theta}{\partial y} / \frac{\partial \theta}{\partial w}=\frac{v_{W}\left(T(y+w)-k h_{0}\right)-v_{W}(T y)}{v_{W}\left(T(y+w)-k h_{0}\right)}
$$

The agent is assumed to have CRRA utility over wealth when he is unconstrained:

$$
v(W)=\frac{W^{1-\gamma^{g}}}{1-\gamma^{g}}
$$

Under this assumption, (8) implies

$$
-\frac{\partial \theta / \partial y}{\partial \theta / \partial w}=\frac{(T y)^{-\gamma}-\left(T(y+w)-k h_{0}\right)^{-\gamma}}{\left(T(y+w)-k h_{0}\right)^{-\gamma}}
$$

Using the definitions of the elasticities in the text, taking logs and rearranging gives

$$
\widehat{\gamma}^{g} \equiv \frac{\log \left[1-\frac{\varepsilon_{\theta, y}}{\varepsilon_{\theta, w}} \frac{w}{y}\right]}{\log \left[1+\frac{w-k h_{0} / T}{y}\right]}
$$

\section{Appendix B: Correction for "Seam Effect"}

When the true unemployment durations are latent, we need to maximize a likelihood function for reported durations rather than the likelihood for actual durations in (17). This appendix develops a likelihood for reported durations using a mixture model to capture the process that generates the reporting errors in the SIPP data.

Suppose that there are two types of individuals in the population: exact reporters and seam reporters. Exact reporters always report job findings exactly on the week that they actually occur; for this group, there is no mismeasurement problem. Seam reporters never report job-findings within a four-month reference period; they effectively report all transitions on the seams between interviews. What remains is to specify which transitions are reported on which seam by seam reporters. Lacking prior information on the nature of the recall process, I make the assumption that seam reporters report job findings that occur in the first half of a reference period on the seam before that period and job findings in the second half of a reference period on the seam after that period. ${ }^{48}$ For example, suppose a seam-reporting agent has his interview seams at 17 weeks, 34 weeks, and 52 weeks after unemployment

\footnotetext{
${ }^{48}$ This pattern would emerge if seam reporters report a constant employment status during the reference period based on whether they spent the majority of that reference period employed or unemployed.
} 
(recall that each reference period lasts for $17-18$ weeks). ${ }^{49}$ If he finds a job between weeks 8 and 25 after unemployment, he reports the transition at week 17; if he finds a job between 26 and 43 weeks after unemployment, he reports the transition on the second seam; and if he finds a job between week 44 and week 55, the end of the search period in the model, he reports the transition on the third seam. Finally, if a spell ends in the first half of the first reference period (in this example, before the ninth week), I assume that all individuals correctly report the duration.

Given this model of recall errors, we can formulate a likelihood function for reported durations as follows. Let $\mu$ denote the fraction of seam reporters. The probability of observing a given duration $d$ is

$$
\operatorname{Pr}(d)=(1-\mu) \operatorname{Pr}(d \mid \text { exact reporter })+\mu \operatorname{Pr}(d \mid \text { seam reporter })
$$

For exact reporters, the probability of observing $d$ coincides with the probability that the true duration of the spell is $d$. To see how the likelihood for the seam reporters is formulated, consider an agent who reports a duration $d$ that coincides with his first seam. Under our model of recall errors, we only know that the true duration lies in the second half of his first reference period (i.e. after $d-8$ ) or the first half of his second reference period (before $d+9)$. The probability of observing $d$ is therefore equal to the probability that the true duration lies between $d-8$ and $d+9$. Hence, we can write a likelihood function for reported durations as follows:

$$
\begin{aligned}
\widetilde{L}(\omega)= & \prod_{i=1}^{I_{1}+I_{2}}\left[\left(1-\mu+\mu\left(d_{i}<\operatorname{seam}_{i}-9\right) \text { onseam }_{i}\right) \prod_{t=1}^{d_{i}}\left(1-p_{t}^{i}(\omega)\right) \prod_{i=1}^{I_{1}} p_{d_{i}+1}^{i}(\omega)\right. \\
& \left.+\mu \text { onseam }_{i}\left(\prod_{t=1}^{\min \left(d_{i}+8, T\right)}\left(1-p_{t}^{i}(\omega)\right)-\prod_{t=1}^{\max \left(d_{i}-9,1\right)}\left(1-p_{t}^{i}(\omega)\right)\right)\right]
\end{aligned}
$$

where onseam ${ }_{i}$ is a dummy variable that indicates whether the agent's duration $d_{i}$ lies on one of his seams, seam $1_{i}$ denotes the week on which agent $i$ 's first seam occurs, and $\left(d_{i}<\operatorname{seam} 1_{i}-\right.$ $9)$ is an indicator variable.

The measurement-error corrected estimator of $\{\omega, \mu\}$ reported in the text maximizes the likelihood function in $(22)$.

\footnotetext{
${ }^{49}$ Note that this is not the only pattern for the seam weeks because agents can report unemployment at any time within a reference period.
} 
FIGURE 1

A Committed Agent's Utility Over Wealth: Theoretical Characterization

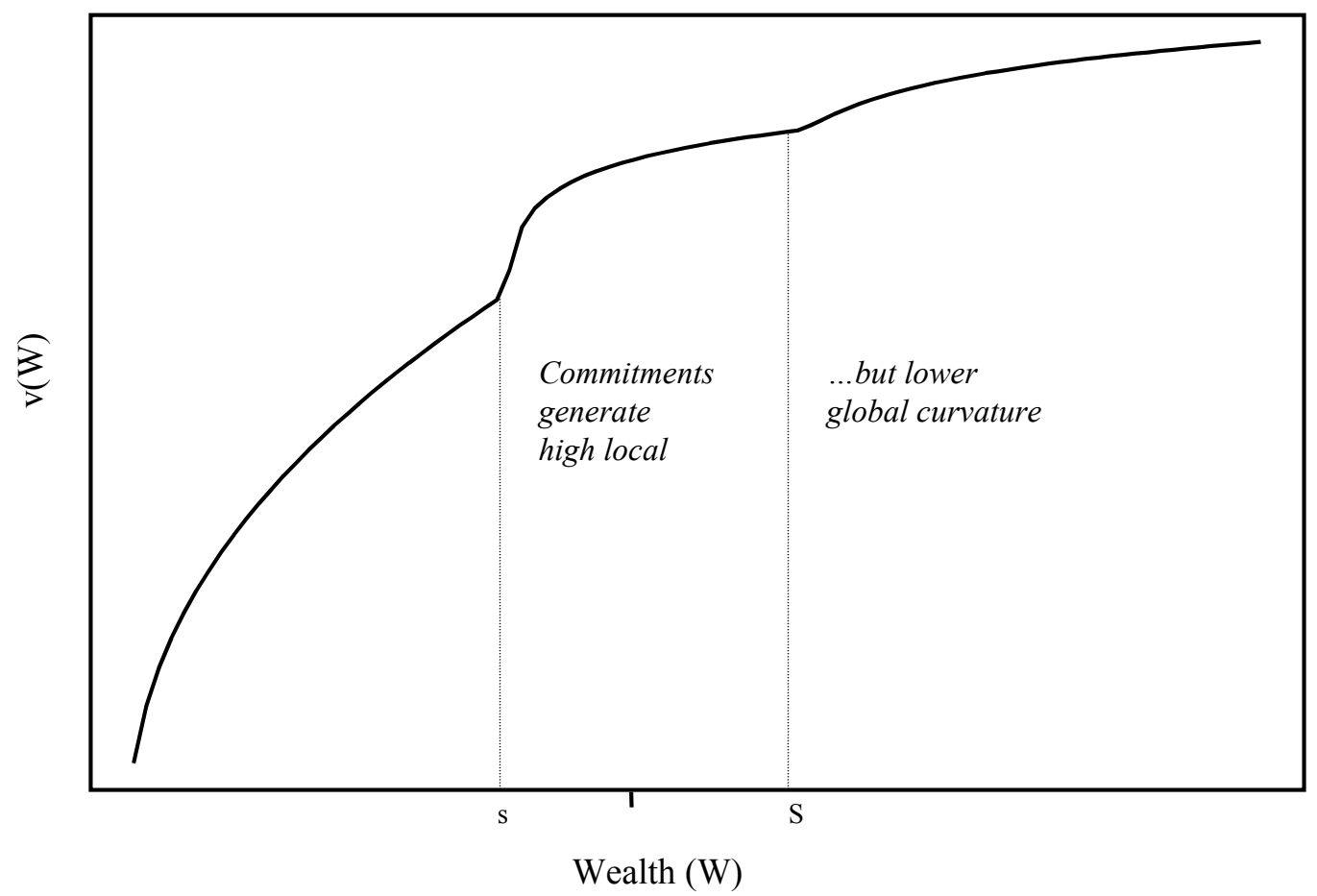

NOTE - Figure plots utility over wealth in second period, after an agent has purchased a home in period 1 . The transaction cost of selling the home makes it optimal not to move iff $W \in(s, S)$. The commitment affects preferences over wealth in two ways: (1) It makes agents locally risk averse by increasing the curvature of utility within the $(s, S)$ band; (2) It creates non-concavities in utility over wealth at $s$ and $S$, creating a gambling motive. 
FIGURE 2

Sample Unemployment Insurance Benefit Paths

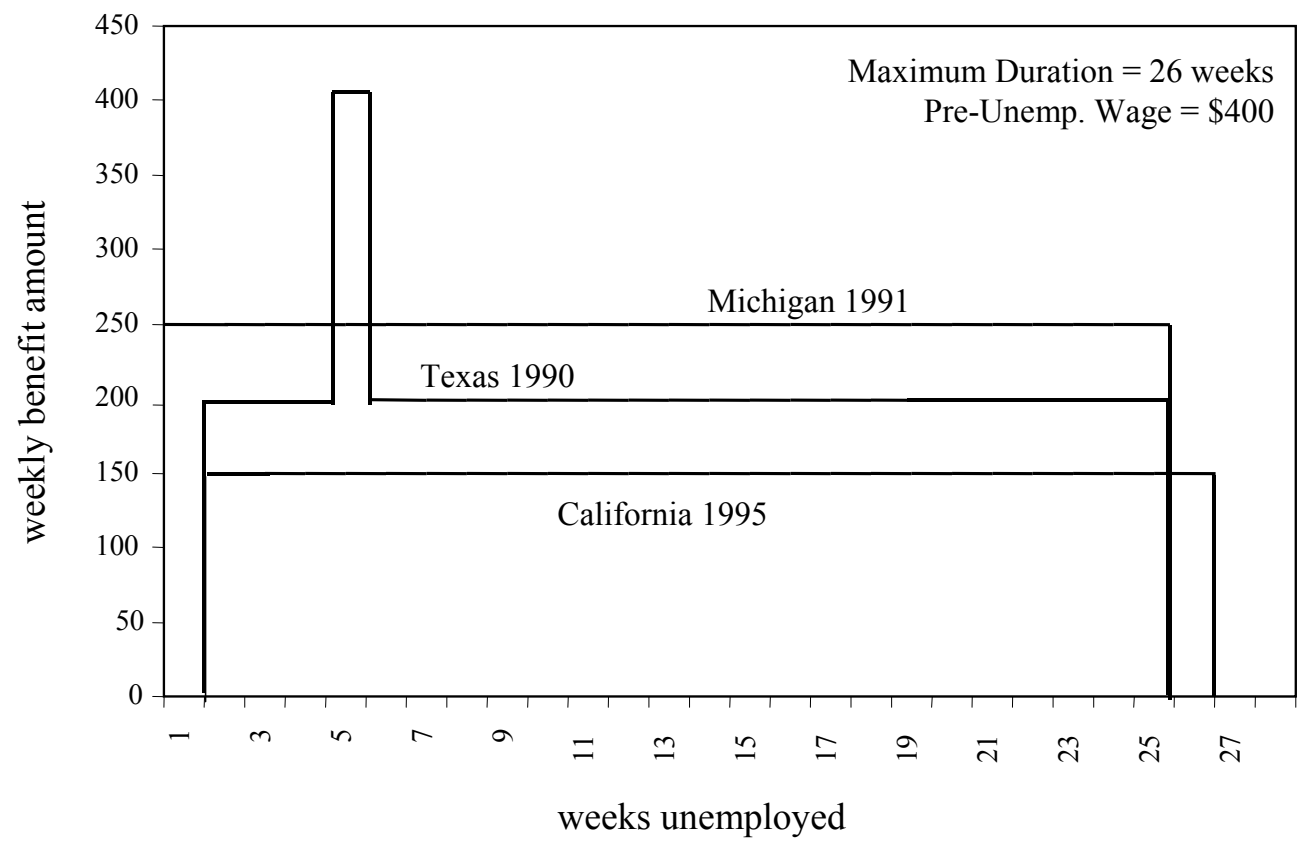

NOTE - Figure plots weekly unemployment insurance benefit payments in 1990 dollars for a claimant earning $\$ 400$ per week over the entire year prior to unemployment. MI has no waiting period; TX has a retroactive payment for the waiting period after 4 weeks of unemployment; and CA has a waiting period and no retroactive provision. Following the notation used in the paper, MI and TX are INC $=1$ states and $\mathrm{CA}$ is an INC $=0$ state. For this claimant, all three states have a maximum duration for UI benefits of 26 weeks; since CA has a one week waiting period, benefits terminate in the $27^{\text {th }}$ week after the job separation. 
FIGURE 3

UI Benefit Rates and Empirical Survival Probabilities

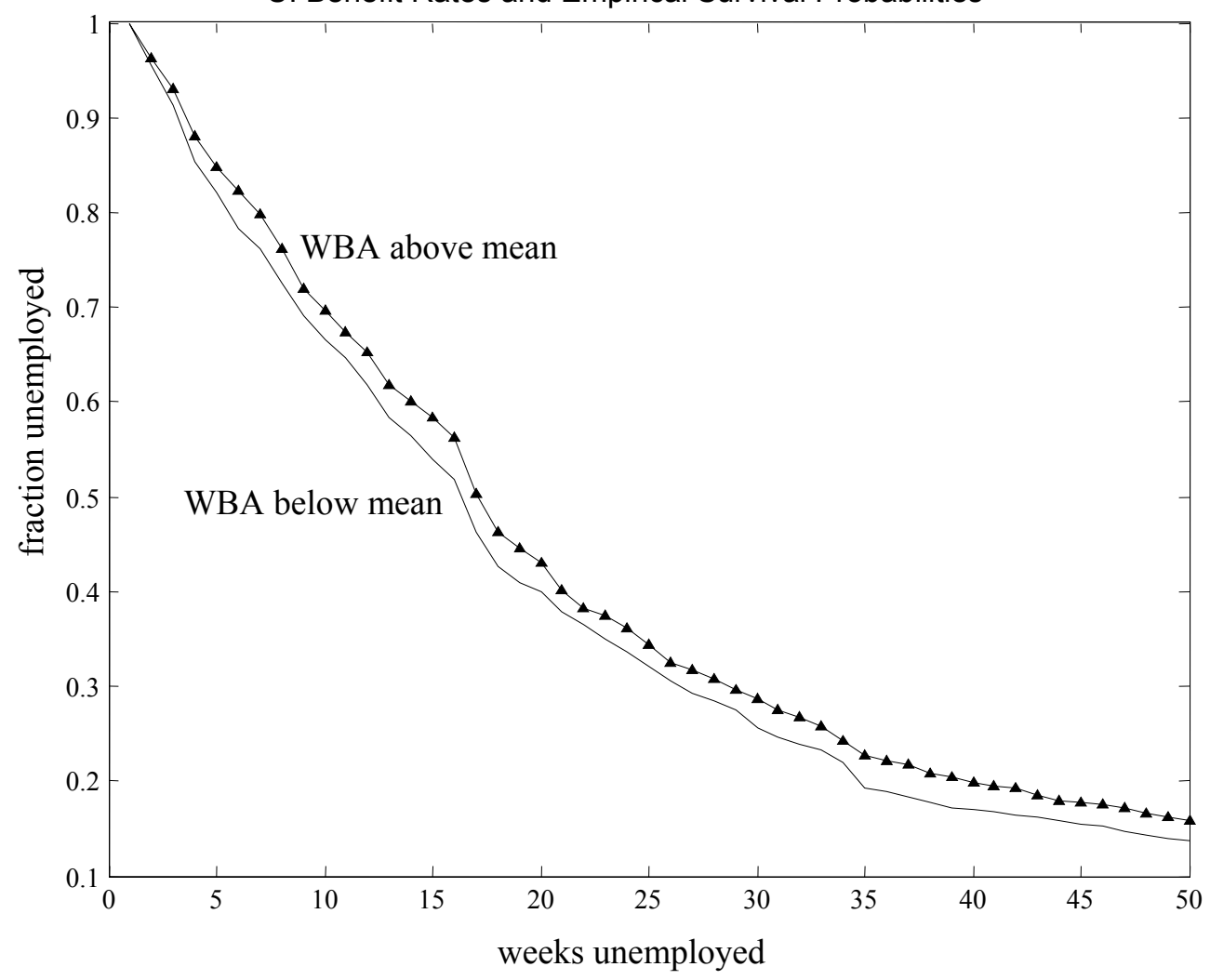

NOTE - Figure plots survival probabilities for two categories of unemployment insurance claimants: those who live in states with average weekly benefit amounts (WBA) below the sample mean and those who live in states with WBAs above the mean. See Table 2 for description of sample selection procedures. 
FIGURE 4

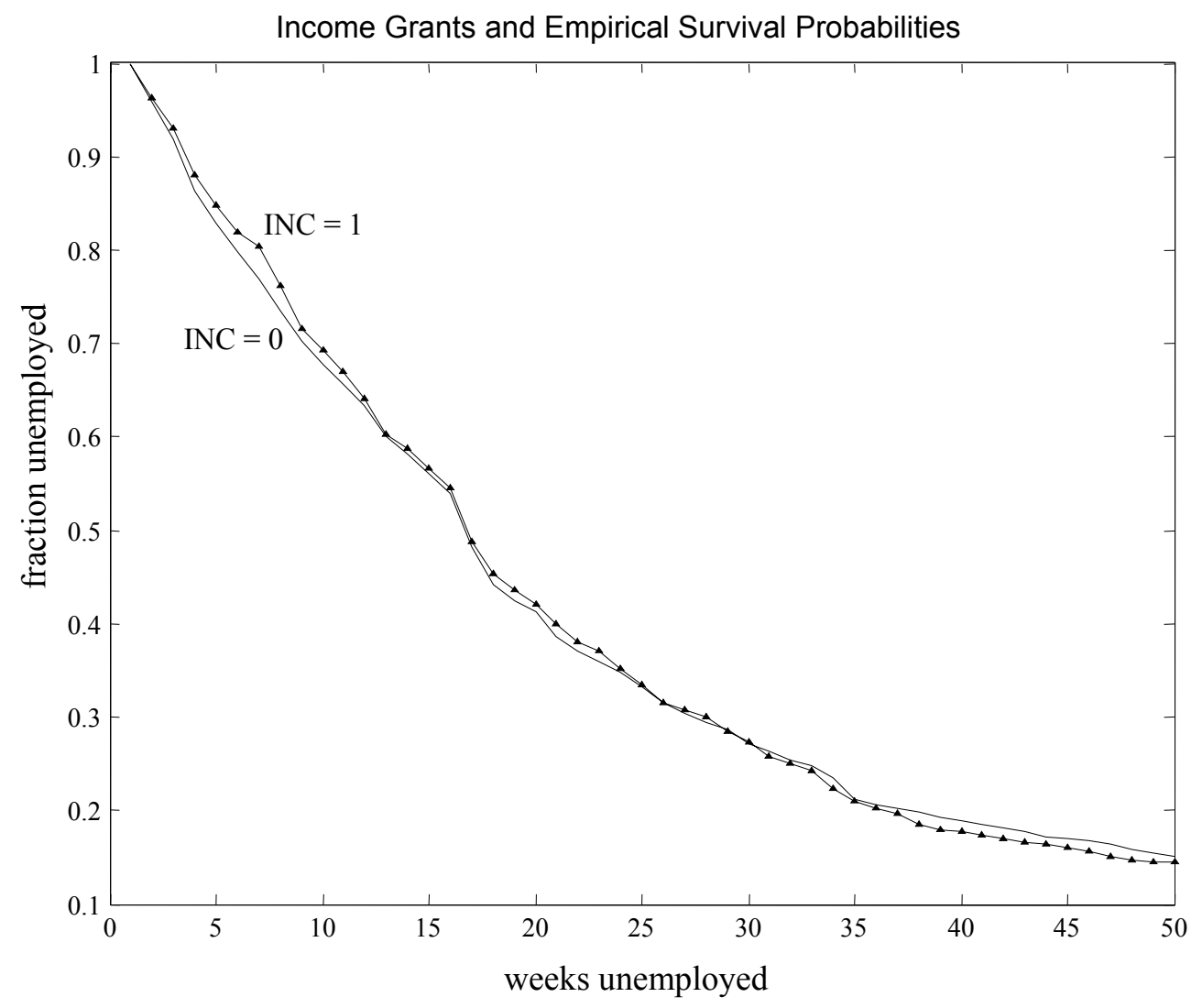

NOTE - Figure plots survival probabilities for two categories of unemployment insurance claimants: those who live in states that have a one-week waiting period for UI benefits and make no retroactive payment for this week $(\mathrm{INC}=0)$ and those who live in states that either have no waiting week or make a retroactive payment $(\mathrm{INC}=$ 1). Claimants in the INC $=1$ states effectively receive an extra week of UI benefits at the beginning of the spell relative to claimants in INC $=0$ states. See Table 2 for description of sample selection procedures. 
FIGURE 5

Empirical vs. Predicted Survival Curves

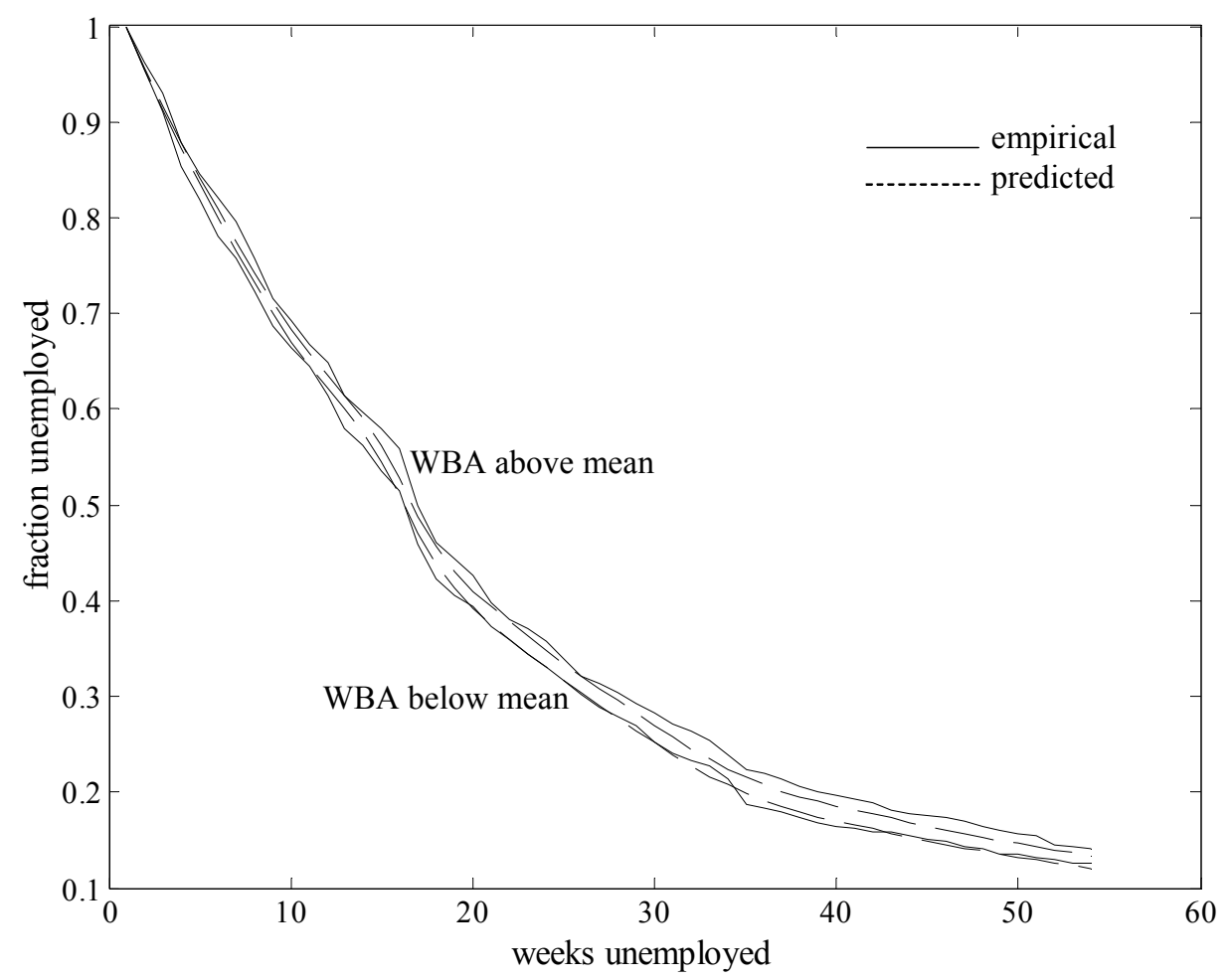

NOTE - Figure shows empirical (solid) and predicted (dashed) survival curves for two categories of UI claimants: those who live in states that have weekly benefit amounts (WBA) below the mean and those who live in states that have WBAs above the mean. The predicted survival curves are based on specification (2) in Table 3, where the estimate of $\gamma^{l}=7.07$. 
FIGURE 6

Empirical vs. Predicted Survival Curves When Local Curvature is Low

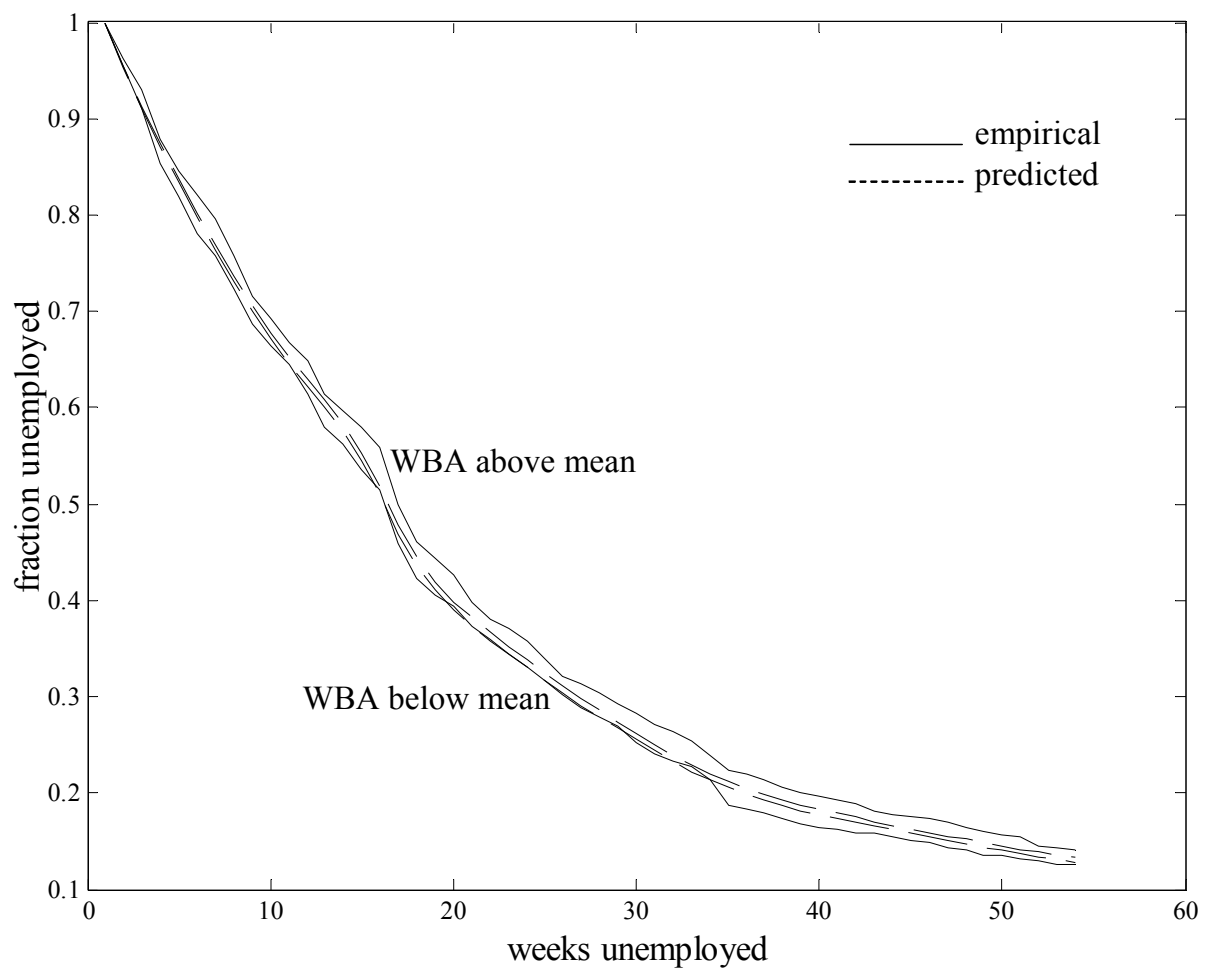

NOTE - Figure shows empirical (solid) and predicted (dashed) survival curves for two categories of UI claimants: those who live in states that have weekly benefit amounts (WBA) below the mean and those who live in states that have WBAs above the mean. The predicted survival curves are based on estimates of the search model without a measurement error correction in which the value of local curvature is constrained to equal $\gamma^{l}=2.5$. All other parameters are unrestricted. 
FIGURE 7

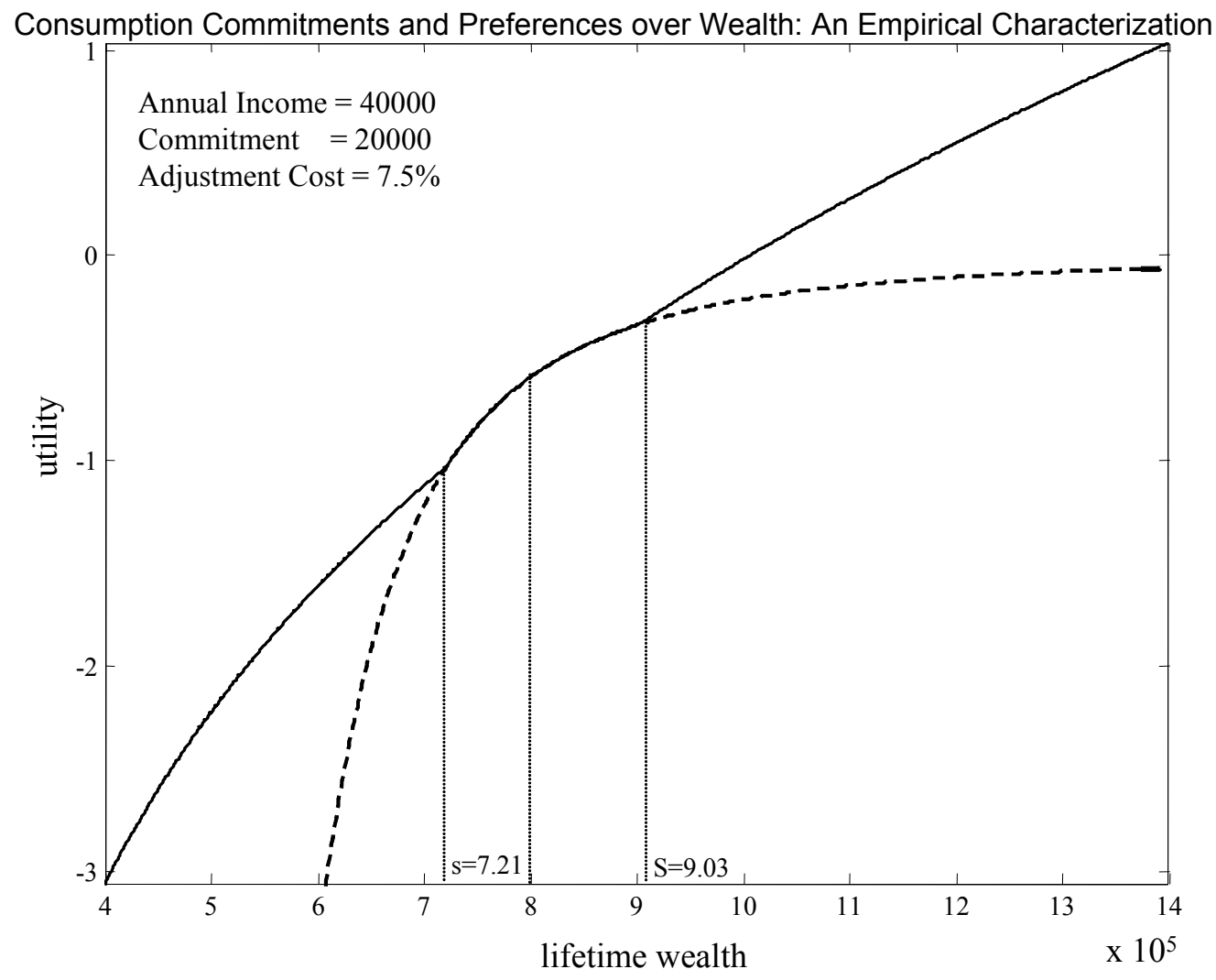

NOTE - The solid curve characterizes utility over wealth of a committed agent based on empirical estimates of the underlying utility function $u(h, f)$ in the dynamic search model. The utility that is plotted has a local curvature of $\gamma^{l}=7.37$, based on the empirical estimates of specification (1) in Table 3, and a global curvature of $\gamma^{g}=1$. The figure assumes that the agent has committed half of his $\$ 40,000$ income prior to entering this period to goods that have an adjustment cost of $k=7.5 \%$. In addition, it assumes that the agent has an infinite horizon and does not face any credit constraints. The empirical estimates imply that such an agent will retain his commitment when his lifetime wealth is between $s=\$ 721,000$ and $S=\$ 903,000$, accommodating wealth fluctuations by adjusting consumption only over the uncommitted good in this region. The dashed curve extends utility in the committed region outside the $(s, S)$ band, showing what utility over wealth would look like if the agent never abandoned his commitments. 
TABLE 1

MEAN HOUSEHOLD EXPENDITURE SHARES

\begin{tabular}{lcccc}
\hline \hline \multirow{2}{*}{ Category } & \multicolumn{4}{c}{ Income Group } \\
\hline Shelter & 0.20 & $\$ 30-40 \mathrm{~K}$ & $>\$ 70 \mathrm{~K}$ & Overall Mean \\
Transport (excluding gas and maint) & 0.12 & 0.16 & 0.21 & 0.20 \\
Utilities, fuels, and public services & 0.10 & 0.07 & 0.16 & 0.16 \\
Health care & 0.09 & 0.06 & 0.04 & 0.07 \\
Education & 0.03 & 0.01 & 0.02 & 0.06 \\
Food & 0.16 & 0.16 & 0.14 & 0.15 \\
Apparel & 0.06 & 0.05 & 0.06 & 0.15 \\
Household supplies and furniture & 0.06 & 0.06 & 0.10 & 0.06 \\
Entertainment & 0.04 & 0.05 & 0.06 & 0.05 \\
Miscellaneous & 0.03 & 0.02 & 0.02 & 0.02 \\
Cash contributions & 0.02 & 0.03 & 0.05 & 0.04 \\
\hline Mean annual expenditure & $\$ 15,369$ & $\$ 32,609$ & $\$ 64,134$ & $\$ 35,930$ \\
Mean take-home pay & $\$ 6,858$ & $\$ 29,720$ & $\$ 90,748$ & $\$ 41,531$
\end{tabular}

NOTE - The values are based on tabulations by the Bureau of Labor Statistics from the 2000 Consumer Expenditure Survey. Take-home pay is defined as gross income net of taxes and mandatory insurance/pension contributions. 
TABLE 2

DESCRIPTIVE STATISTICS FOR UI CLAIMANTS FROM THE SIPP

\begin{tabular}{lrrrrr}
\hline \hline & & & Standard & & \\
Variable & Mean & Median & Deviation & Minimum & Maximum \\
\hline Age & 37.00 & 35.00 & 11.08 & 18.00 & 64.00 \\
1 = Married & 0.61 & 1.00 & 0.49 & 0.00 & 1.00 \\
Education (years) & 12.07 & 12.00 & 3.06 & 0.00 & 18.00 \\
Dependents & 0.52 & 0.00 & 0.96 & 0.00 & 8.00 \\
Pre-unemployment weekly wage & 413.96 & 355.11 & 272.78 & 0.00 & $3,393.81$ \\
Annual pre-unemp family income & $42,195.51$ & $35,344.00$ & $35,621.44$ & 0.00 & $1,351,164.00$ \\
Pre-unemp home equity & $32,053.37$ & $9,440.32$ & $49,494.13$ & $-49,486.39$ & $431,482.60$ \\
Pre-unemp liquid wealth & $22,715.79$ & $2,027.97$ & $64,997.21$ & $-8,973.50$ & $1,153,178.00$ \\
Liquid wealth net of unsec. debt & $18,441.26$ & 186.32 & $66,588.72$ & $-651,057.00$ & $1,153,178.00$ \\
Weekly Ul benefit amount & 165.80 & 162.30 & 50.46 & 46.10 & 354.18 \\
1 = Waiting period & 0.86 & 1.00 & 0.35 & 0.00 & 1.00 \\
1 = Retroactive payment & 0.17 & 0.00 & 0.38 & 0.00 & 1.00 \\
Maximum potential duration (weeks) & 32.11 & 26.00 & 6.42 & 22.00 & 39.00 \\
State unemployment rate & 6.60 & 6.50 & 1.70 & 2.30 & 14.10 \\
Weeks to job finding or censoring & 20.89 & 16.00 & 21.03 & 2.00 & 171.00 \\
1 = Censored & 0.22 & 0.00 & 0.41 & 0.00 & 1.00 \\
\hline
\end{tabular}

NOTE - The values are based on tabulations from SIPP panels spanning 1985-2000. The sample consists of the 4,457 prime-aged males who (1) took up unemployment insurance benefits within one month of a job separation, (2) reported searching for a job at some point during the spell, (3) never reported that they were on temporary layoff, and (4) were unemployed for more than one week. Wealth data are collected only in certain topical modules and are therefore available for only 2,530 observations. Liquid wealth is defined as total wealth minus home equity and vehicle equity. All monetary variables are in 1990 dollars. 
TABLE 3

STRUCTURAL ESTIMATES OF SEARCH MODEL

\begin{tabular}{|c|c|c|c|c|}
\hline Parameter & $\begin{array}{c}\text { (1) } \\
\text { Base Case } \\
\end{array}$ & $\begin{array}{c}(2) \\
\text { No Seam } \\
\text { Correction } \\
\end{array}$ & $\begin{array}{c}(3) \\
\text { Restricted } \\
\text { Baseline } \\
\end{array}$ & $B=10,000$ \\
\hline Local curvature $\left(\gamma^{\top}\right)$ & $\begin{array}{c}7.3632 \\
(2.07)\end{array}$ & $\begin{array}{c}7.0668 \\
(2.93)\end{array}$ & $\begin{array}{c}7.3826 \\
(2.79)\end{array}$ & $\begin{array}{c}6.1538 \\
(2.47)\end{array}$ \\
\hline Convexity of search effort $(\theta)$ & 1.5455 & 1.5216 & 1.5436 & 1.5672 \\
\hline Disutility of labor $\left(\psi_{\$}\right)$ & 72.5300 & 77.5746 & 68.9114 & 48.0419 \\
\hline \multicolumn{5}{|l|}{ Baseline Job Finding Probs: } \\
\hline$\alpha_{1}$ & 0.0393 & 0.0369 & 0.0378 & 0.0266 \\
\hline$\alpha_{5}$ & 0.0363 & 0.0341 & & 0.0251 \\
\hline$\alpha_{9}$ & 0.0378 & 0.0334 & 0.0363 & 0.0261 \\
\hline$\alpha_{13}$ & 0.0349 & 0.0291 & 0.0356 & 0.0240 \\
\hline$\alpha_{17}$ & 0.0326 & 0.0369 & & 0.0224 \\
\hline$\alpha_{21}$ & & 0.0284 & & \\
\hline$\alpha_{25}$ & 0.0319 & 0.0270 & 0.0311 & 0.0219 \\
\hline$\alpha_{32}$ & 0.0282 & 0.0270 & & 0.0198 \\
\hline$\alpha_{40}$ & 0.0208 & 0.0199 & 0.0222 & 0.0146 \\
\hline$\alpha_{48}$ & 0.0215 & 0.0192 & & 0.0146 \\
\hline$\alpha_{55}$ & 0.0171 & 0.0178 & 0.0185 & 0.0125 \\
\hline State unemployment rate $\left(\alpha_{u}\right)$ & -0.0460 & -0.0445 & -0.0459 & -0.0775 \\
\hline Fraction of seam reporters $(\mu)$ & 0.3283 & & 0.3258 & 0.3197 \\
\hline Log likelihood value & -12688.74 & -13703.72 & -12690.95 & -12695.76 \\
\hline Sample size & 4457 & 4457 & 4457 & 4457 \\
\hline
\end{tabular}

NOTE - Each column reports estimates of the dynamic job search model. Standard errors, reported in parentheses for $\gamma^{l}$, are derived by inverting a likelihood ratio test. Columns 1, 3, and 4 include a correction for mismeasurement of unemployment durations to account for the seam recall problem discussed in the text. In columns 1-3, exogenous parameters for the search model are as follows: weekly wage $w=400$, commitment $\bar{h}=200$, pre-unemployment assets $a=500$, weekly discount rate $\beta=0.9^{1 / 50}$, disutility of labor $\psi_{\$}=100$, welfare payment $\underline{w}=100$, and borrowing/late-payment constraint $\bar{B}=11,000$. In column $4, \bar{B}=10,000$. See notes to Table 2 for description of sample selection procedures. 